\title{
HIBRIDAÇÃO INTERESPECÍFICA NO GÊNERO Qucumis L.
}

\author{
MARIA ELISA AYRES GUIDETTI ZAGATTO PATERNIANI \\ Engenheira Agrônoma
}

Orientador: Prof. Dr. CYRO PAULINO DA COSTA

\begin{abstract}
Dissertação apresentada à Escola Superior de Agricultura "Luiz de Queiroz", da Universidade de São Paulo, para a obtenção do título de Mestre em Agronomia. Área de Concentração: Genética e Melhoramento de Plantas.
\end{abstract}

$P|R A C| C A B A$

Estado de São Paulo - Brasil

Abril - 1988 
A memória de meu pai,

à misha mäe,

aos meus familiares e

ao meu esposo José Euclides,

companheiro de todas as horas,

DEDICO. 


\section{AGRADECIMENTOS}

A Deus, por iluminar meus passos nessa caminhada.

Ao Prof. Dr. Cyro Paulino da Costa, pela orientação e ensinamentos recebidos.

$\bar{A}$ FAPESP e ao CNPq, pela concessao das bolsas de estudo.

Aos professores e funcionários do Departamento de Genética da Escola Superior de Agricultura "Luiz de Queiroz" (USP), pelos conhecimentos adquiridos e facilidades concedidas.

Aos Departamentos de Biologia e Agricultura da Faculdade de Engenharia de Ilha Solteira, da Universidade Estadual Paulista, pela receptividade e cessão de área experi mental.

Ao Prof. Dr. Ernesto Paterniani, pela confecção do "Summary" e pelo incentivo com seu exemplo de grande mestre e melhorista de plantas.

A. Profa. Dra Maria Ruth Buzzato Alleoni, pelo estimulo e amizade. 
Aos funcionários do Departamento de Genética Alcides Martins, João Araújo e colaboradores, pelo auxílio na condu çao dos trabalhos de campo.

Ao colega Ailton Ribeiro, pelas sugestões e revisão do manuscrito, colaboração e amizade.

As colegas Arlete B. Marchi e Ingrid B. I. Barros, pe lo. apoio e carinho.

Aos demais colegas do Curso de Pós-Graduação, pelo companheirismo.

E a todos que direta ou indiretamente contribuiram para à realização deste trabalho.

A Autora. 
Pàgina

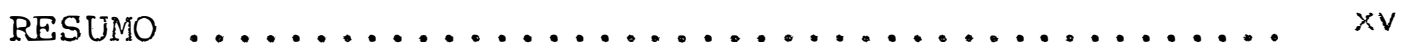

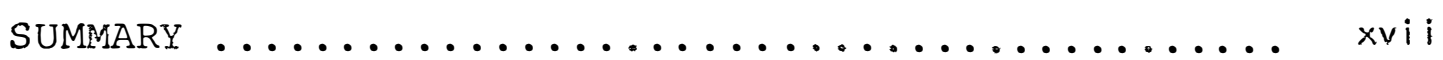

1. INTRODUÇÃO $\ldots \ldots \ldots \ldots \ldots \ldots \ldots \ldots \ldots \ldots \ldots \ldots \ldots \ldots \ldots \ldots \ldots \ldots \ldots$

2. REVIST̃O DE LITERATURA .................... 3

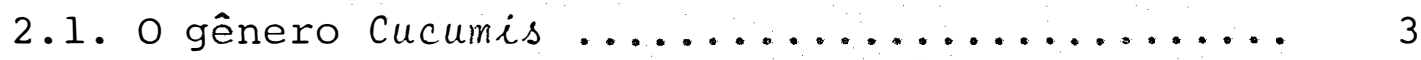

2.1.1. Origem, distribuição geográfica e espé cies relacionadas ............... 3

2.1.2. Fontes de resistência a doenças è pra-

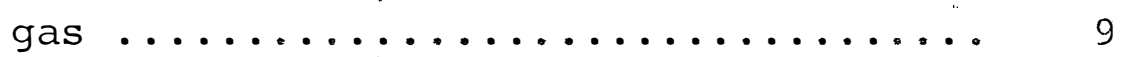

2.2. Hibridação interespecífica ............. 10

2.2.1. Considerações gerais ............. 10

2.2.2. Hibridação e relacionamento entre espẹ cies de Cucumis ................ 14

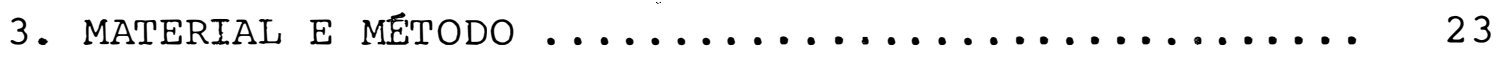

3.1. Locais de investigação ................ 23

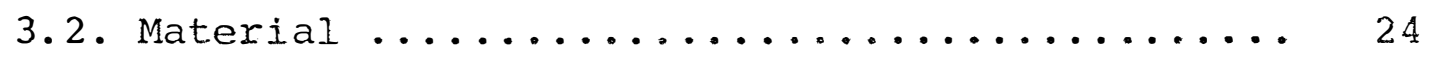

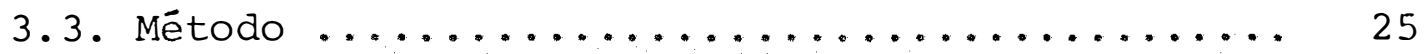

3.3.1. Procedimento de obtenção de mudas..... 25

3.3.2. Tratos culturais .................. 25

3.3.3. Hibridação interespecifica.......... 26 
3.3.4. Obtenção das sementes $\ldots \ldots \ldots \ldots \ldots \ldots .27$

3.3.5. Avaliação do potencial. de produção de frutos de alguns híbridos interespecificos no gênero Cucumes ............. 28

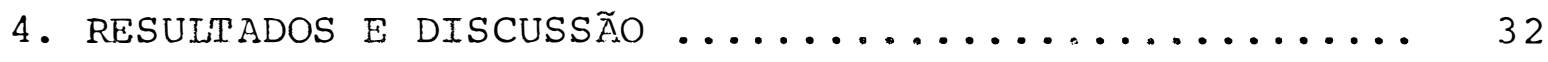

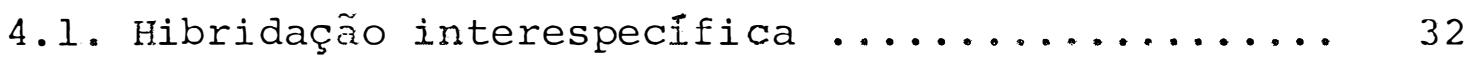

4.1.1. Cruzamento de C. anguria x C. africanus. 34

4.1.2. Cruzamento de C. anguria x C. dipsaceus. 39

4.1.3. Cruzamento de C. anguria $\times$ C. ficifolius 40

4.1.4. Cruzamento de C. anguria x C. longipes.. 42

4.1.5. Cruzamento de C. anguria x C. myriocarpus. 46

4.1.6. Cruzamento de C. africanus $x$ C. myriocarpus ......................... 51

4.1.7. Cruzamento de C. africanus $x$ C. longipes 53

4.1.8. Cruzamento de C. dipsaceus $x$ C. ahrica-

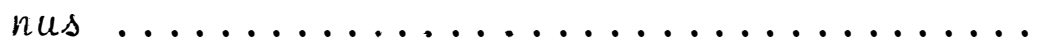

4.1.9. Cruzamento de C. longipes x C. myriocar-

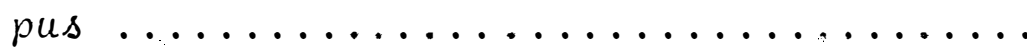

4.1.10.Cruzamento de C. metuliferus com outras espécies de cucumis sp.......... 55

4.2. Auto-fecundações das espécies progenitoras utilizadas na hibridação interespecífica........

4.3. Avaliação do potencial de produção de frutos de alguns hỉbridos interespecíficos no gênero $\mathrm{Cu}$ -

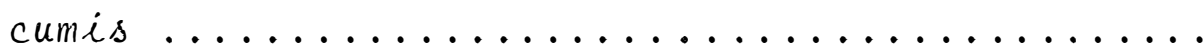


vii i

Pägina

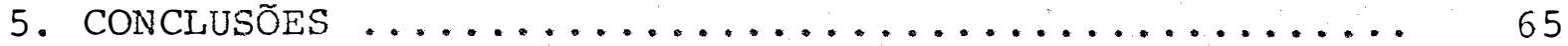

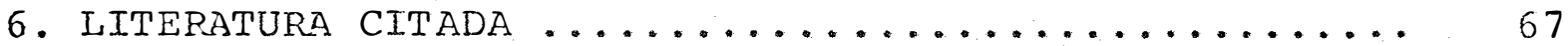


TABELA NO

01 Espécies de Cucumis, taxonomistas e nümero de cromossomos (MALIICK \& MASUI, 1986) ....

02 Espēcies, āesignação e procedência das introduções de cucumis utilizadas na hibridą ção interespecífica. Piracicaba, SP, 1986.

03 Cruzamentos realizados. Nas linhas aparecem espécies utilizadas como progenitor femini no; nas colunas, espécies utilizadas como progenitor masculino. Piracicaba, SP, 1986

04 Híbridos interespecíficos e seus respectivos progenitores avaliados quanto ao poten cial de produção. Piracicaba, SP, $1986 \ldots$.

05 Hibridação interespecífica de C. anguria $\mathrm{x}$ C. africanus expressa em pegamento de frutos (\%). Piracicaba, SP, 1986..........

Hibridação interespecífica de C.africanus x C. anguria, expressa em pegamento de fru

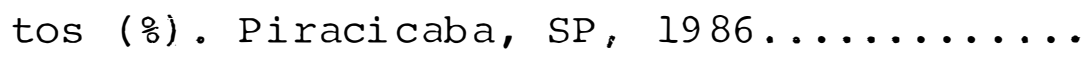

07 Obtenção das gerações $F_{2}$ e de retrocruzamento para $C$. anguria a partir da hibricação interespecífica $C$. anguria $\times$ C, afri canus, expressa em pegamento de fruto (\%) Ilna Soltejra, SP, $1987 \ldots \ldots \ldots \ldots \ldots$ 
08 Hibridação interespecifica de C. anguria $x$ C. dipsaceus expressa em pegamento de fruto (응. Piracicaba, $S P, 1986 \ldots \ldots \ldots \ldots \ldots \ldots$

09 Hibridação interespecifica de C. anguria $x$ c. bicifolius expressa em pegamento de fru-

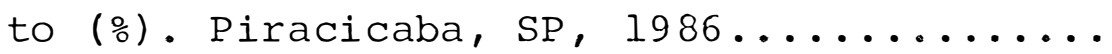

10 Obtenção das gerações $F_{2}$ e de retrocruzamen to para $C$. anguria a partir da hibridação interespecifica $C$. anguria x C. ficifolius, expressa em pegamento de fruto (\%). Ilha

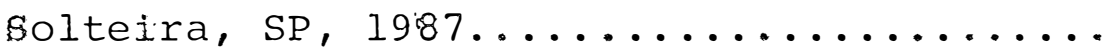

11 Hibridação interespecífica de C. anguria $x$ C. longipes expressa em pegamento de fruto

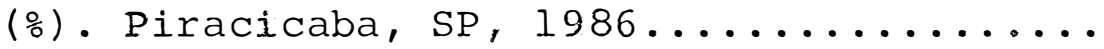

12 Hibridação interespecífica de $C$. longipes $x$ C. anguria expressa em pegamento de fruto (ㅇ). Piracicaba, SP, 1986..............

13. Obtenção das gerações $F_{2}$ e de retrocruzamen to para C. anguria a partir da hibridação interespecifica $C$. anguria $\times C$. longipes ex pressa em pegamento de fruto (\%). Ilha Sol-

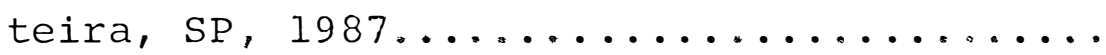


Hibridação interespecífica de C. anguria $\mathrm{x}$ C. myriocarpus expressa em pegamento de fru

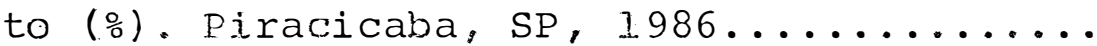

Hibridação interespecífica de C. myriocar pus $\times C$. anguria expressa em pegamento de

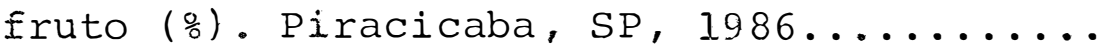

Obtenção das gerações $F_{2}$ e de retrocruzamen to para $C$. anguria a partir da hibridação interespecífica $C$. anguria $\times$ C. myriocarpus expressa em pegamento de fruto (\%). Ilha Solteira, SP, $1987 \ldots \ldots \ldots \ldots \ldots \ldots \ldots$ Hibridação interespecífica de C. africanus x C. myriocarpus (e recíproco) expressa em pegamento de fruto (ㅇ). Piracicaba, SP, 1986

18 Hibridação interespecífica de C. africanus $x$ C. longipes (e recíprocos) expressa em pe gamento de fruto (ㅇ). Piracicaba,SP, 1986..

19 Hibridação interespecífica de C. dipsaceus x C. africanus expressa em pegamento de fruto (ㅇ). Piracicaba, SP, 1986.......... 
20 Hibridação interespecífica de $C$. longipes $x$ C. myriocarpus ( e recjpzocos) expressa em pegamerto de fruto (ㅇ). Piracicaba, SP, 1986

21 Hibridação interespecífica utilizando-se C. metuliferus expressa em pegamento de fruto(\%) Piracicaba, SP, $1986 \ldots \ldots \ldots \ldots \ldots \ldots \ldots$

22 Auto-fecundações das espécies progenitoras utilizadas na hibridação interespecífica expressas em pegamento de fruto (으). Piracicaba, $s p, 1986 \ldots \ldots \ldots \ldots \ldots \ldots \ldots \ldots \ldots \ldots \ldots \ldots \ldots \ldots \ldots \ldots \ldots \ldots$

23 Quadrado mëdio de nümero de frutos por parce la, rendimento em quilograma por parcela e estimativas de amostras tomadas ao acaso de 5 frutos por colheita e por parcela para peso médio em gramas, diâmetro e comprimento do fruto em centimetros de cucumis anguria I., espécies selvagens relacionadas e híbridos interespecíficos. Piracicaba, SP, 1986.. 
24 Médias de nümero de frutos pox parcela, rendimento em quilograma por parcela e estimativas de amostras tomadas ao acaso de 5 frutos por colheita e por parcela para peso médio em gramas, diāmetro e comprimento do fruto em centímetros de Cucumis anguria L., espécies selvâ gens relacionadas e híbridos interespecíficos.

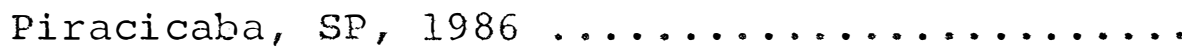


01 C. africanus, C. anguria e hibridos $E_{1}$ inter-

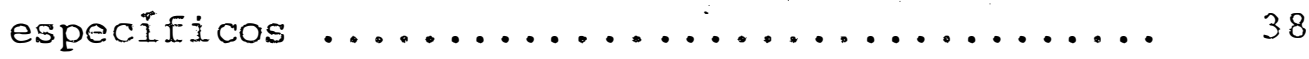

02 C. anguria, c. ficifolius (segundo a classifi

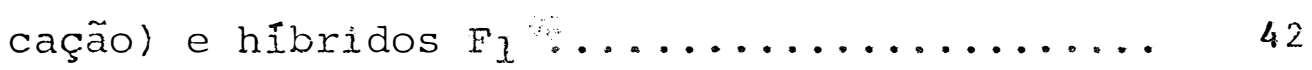

03 C. longipes, $C$. anguria e hibridos $F_{1}$ interes pecificos........................

04 C. anguria, C. myriocarpus e hibridos $F_{1}$ interespecificos $\ldots \ldots \ldots \ldots \ldots \ldots \ldots \ldots \ldots \ldots \ldots \ldots \ldots \ldots$ 
HIBRIDACGAO INTERESPECTFICA NO GENERO Cucumis L.

AlTORA: Maria Elisa Ayres Guidetti Zagatto Paternani ORIENTADOR: Prof. Dr. Cyro Paulino da Costa

\section{RESUMO}

No presente trabalho foram realizados cruzamentos entre espécies selvagens de origem africana do gêne ro Cucumis e o maxixe ( $C$, anguria), com o objetivo de avaliar o grau de relacionamento interespecífico, visando ao aumento da variabilidade genética em populações da espécie cultivada. Posteriormente, foram obtidas gerações segregan tes a partir destes cruzamentos interespecíficos, para eventual utilização em trabalhos de melhoramento de maxixe. Foram efetuadas também hibridações entre as espécies selva gens, para estudos de compatibilidade dentro do gênero.

A relação da hibridação interespecífica foi avaliada atravês da porcentagem de pegamento de frutos, quantidade e qualidade de sementes produzidas e viabilidade da planta $F_{I}$ obtida.

Plém disso, foi conduzido um ensaio preliminar de potencial de produção, comparando-se alguns hỉbri-cos interespecíficos com os respectivos progenitores quanto a componentes de produção. 
cluiu-se que:

- As espécies C. anguria, C. africanus, C. longipes e C. myriocarpus são proximamente relacionadas.

- C. anguria e C. dipsaceus são incompativeis.

- C. metuliferus não se relaciona com as espécies utilizadas.

- Todos os híbridos $\mathrm{F}_{I}$ interespecíficos apresentaram caracte rísticas fenotípicas intermediārias aos progenitores diferindo destes quanto à coloração, espiculosidade a ao comprimento do fruto.

- Foi possível a obtenção de populações segregantes $F_{2}$ e de retrocruzamento para $C$. anguria a partir dos híbridos $F_{1}$ interespecificos $C$. anguria $\times$ C. africanus, C. anguria $x$ C. Longipes e C. anguria x C. myriocarpus, representando grande potencial para utilização no melhoramento do maxixe. 


\section{INTERSPECIFIC HYBRIDIZATION IN cucumis L.}

AUTHOR: Maria Elisa Ayres Guidetie Zagatto Paterniani ADVISER: Prof. Dit. Cyro Paulino da Costa

\section{SUMMARY}

Wild species of African origin of the genus Cucumis were crossed to gherkin (c. anguria) in order to evaluate the degree of interspecific relationship that could be used to increase the genetic variability of the cultivated specie. From the interspecific crosses segregating generations were obtained that eventually could be used in gherkin breeding. Interspecific crosses were also obtained for compatibility studies within the genus.

The degree of interspecific hybridization was evaluated through the percentage of fruit setting, quantity and quality of seeds obtained, and viability of the FI plants.

Furthermore a preliminar yield trial to evaluate the yielding potential, specially yield components, of some interspecific hybrids and their parents was carried out.

The experimental results and observations permit the following conclusions:

- The species C. anguria (Gherkin), C. africanus, C. longipes and C. muriocarpus are closely related. 
- C. anguria and C. dipsaceus are incompatible.

- C. metuliferus is not closely related to any other species utilized.

- All $F_{1}$ interspecific hybrids showed phenotypic characteristics intermediate in relation to the parents, being different regarding color, spiculation and lenght of the fruits.

- It was possible the obtaintion of segregating $F_{2}$ populations and backcrosses to $C$. anguria from the interspecific $\mathbb{F}_{1}$ hybrids C. anguria $\times C$. africanus, $C$. anguria $\times C$. Pongipes and C. anguria $\times$ C. myriocarpus which represent a great potential for gherkin breeding. 


\section{INTRODUÇAO}

o gênero Cucumis compreende cerca de 30 espécies, das quais três são cultivadais como olerícolas: o me lão (C. melo), o pepino (C. sativus) e o maxixe (C. anguria).

o cultivo do maxixe se dá esporadicamente em áreas concentradas em regiões de clima tropical e sub-tropical, principalmente no Caribe e no Brasil (ESQUINAS-ALCAZAR \& GULLICK, 2983). Aqui, os frutos imaturos são consumidos di retamente na forma de salada ou picles ou preparados como um cozido popular, a "maxixada".

Inicialmente considerado nativo das Amëricas, C. anguria ê originária da Âfrica, segundo relatos de MEEUSE (1958), tratando-se de um mutante não-amargo da espécie selvagem africana $C$. longipes Hook. f. e introduzida no Brasil. há cerca de 300 anos atravēs do tráfico de escravos.

Dentre as espécies cultivadas do gênero, o maxixe apresenta maior compatibilidade com as espëcies selvagens de Cucumis da Africa, embora todos os estudos de hibridação interespecifica se utilizem de introduções africa-nas de C. anguria. 
As espécies selvagens de cucumis produzen frutos amargos, numa grande diversidade de tamanho, cor e espiculosidade. Hã muita controvérsia quanto à classificação dessas espécies, provocando dificuldades em trabalhos de melhoramento, que visam principalmente à incorporação de resistên cia a doenças e pragas do germoplasma selvagem às espécies cultivadas.

As populações brasileiras de $C$. anguria se caracterizam pela produção de frutos grandes, lisos e semamargor. No entanto, ocorre pequena variabilidade genética entre populações para caracteres de planta e fruto, indicando que a base genética é bastante estreita (YOKOYAMA, 1987). Uma das alternativas para se promover e aumentar a variabili dade entre populações é a hibridação interespecífica.

o presente trabalho tem por objetivo estudar o grau de compatibilidade e relacionamento entre espécies selvagens africanas de Cucumis e introduções de $C$. anguria de procedência brasileira através da hibridação interespecífica, visando a ampliar a diversidade genética do maxixe, tem como avaliar o relacionamento interespecífico do gênero com base em espécies de origem africana. Pretende-se também obter populações segregantes a partir dos cruzamentos interespecíficos para eventual emprego em trabalhos de melhoramen to de maxixe ou pàra estudos de genética bāsica de C. cuguria. 


\section{REUISAO DE LITERATURA}

\section{1. o gênero cucuràs}

\subsubsection{Origem, distribuiçāo geogräfica e espẹcies relacionadas}

As espëcies do gênero Cucumis distribuen-me em duas āreas geográficas distintas: uma cobre o leste da África, a Península Arábica e o leste do Mediterrâneo lespẹ cies do Grupo Africano) e a outra situa-se na India, ao suj. e leste do Himalaia (espécies do Grupo Asiático).

Segundo LEPPIK (1966), a área na qual se dis tribuem as espécies do Grupo Africano tem a maior concentra ção de espécies selvagens que mostram características fiłogenéticas do gênero, podendo ser considerada o centro de origem primário de cucumis. Do centro primário, as espë̈cies disseminaram em muitas direções e hoje são encontradas em diversas regiões. Algumas se moveram para o sul, em vastas áreas de gramineas e savanas do sul da Africa. Aí formą ram um centro secundário, com muitas espécies. rasteiras, como C. heptadactylus, C. leptodermis e C. myriocarpus. Du- 
tro grupo de espécies moveu-se para leste e formou um centro terciário na India, onde se encontram as espécies de $C$. hard wickii e c. sativus. Outro centro secundärio citado pelo autor, a América do Sul tem $C$. anguria L. como principal representante.

o centro de origem primário do melão é desconhecido, embora sejam reconhecidos centros secundärios ná India, Pérsia, Irã, sul da Rússia e China.

MALLICK \& MASUI (1986) consideram C. metulífe rus o ancestral comum a todas as espécies de cucumis co nhecidas. Segundo estes autores, a dispersão das espécies formou centros gênicos e a partir desses centros a disse minação se deu através de animais e do homem.

As espécies do Grupo Africano apresentam nưne ro bäsico de cromossomos $x=12$, enquanto que as espécies do Grupo Asiático possuem o nümero básico $x=7$. A evolução do gênero, em particular quanto à existência de dois nümeros básicos de cromossomos, não é clara. BHADURI \& BOSE(1948) assumem que espécies com 14 cromossomos deram origem às espécies com 24 cromossomos por fragmentação. 'I'RIVEDI \& ROY (1970), no entretanto, são de opinião que, por fusão de cromossomos com centrômero sub-terminal, espécies com 24 originaram espécies com 14 cromossomos.

Poucos trabalhos são encontrados descrevendo 
éspécies de Cucumis. A. ünica monografia apresentando a descrição e classificação das espécies foi feita por COGNIAUX (1924), citado por DEAKIN et alie (1970), baseada em espëcies de herbärio. Estudos de sistemática por taxonomistas têm reduzido muitas espëcies de Cogniaux a sinônimos e inclusive alocado espécies para outro gênero.

Diversos autores relatam controvérsias na identificação de espécies gerando dificuldades nos trabathos de melhoramento de Cucumis (VISSER et alii, 1980; KHO et alii, 1981; LEEUWEN \& NIJS, 1980; DEAKIN, BOHN \& WHITAKER, 1971).

LEEUWEN \& NIJS (1980) atribuem os erros de classificação às descrições inadequadas baseadas em espëcies de herbários, cobrindo apenas parte da variabilidade intraespecífica e às condições de cultivo, resultando que a intexpretação de nomes de taxa de Cucumis varia de um trabalho para outro.

DEAKIN, BOHN \& WHITAKER (1971) apresentam descrições de 16 espécies e através de relações de compatibilidade propõem a divisão em 4 grupos: (1) grupo anguria, incluindo as espécies africanas C, africanus, C. arguria, var. anguria, C. anguria var. longipes, C. dipsaceus, $C$. leptodermis, C. myriocarpus, C. prophetarum, C. zeyheri, C. ficifolius e C. heptadactglus; (2) c. metuliferus; (3) espécies asiáticas $C$. hardwickii e C. sativus; (4) espécies 
africanas $C$. humifructus, $C$. melo, $C$. sagittatus e $C$. dinteri, que são mais compatżveis entre si do que com qualquer ou tra espēcje estudadà.

Recentemente, Jeffxey (1980) citado por NIJS \& VISSER (1985), estabeleceu a divisão do gênero em dois sub-gêneros: Sub gênero I, Cucumis, com número de cromosso mos $\mathrm{x}=7$ e Sub-gênero II, Helo, com $\mathrm{x}=12$. Ele dividiu ain da o ültimo sub-gênero em quatro grupos, que não cruzam entre si e diferem em características de fruto, como se segue: Grupo 1, contendo somente C. metuliferus; Grupo 2, denominado "grupo anguria", contendo cerca de 20 espécies relacionadas; Grupo 3, o "grupo melo", representado apenas por C. melo e Grupo 4, consistindo somente de C. hirsuius.

MAIJICK \& MASUI (1986) apresentam uma revissão de classificação das espécies com os nomes dos autores que as relataram (Tabela 1$)$.

As espécies cultivadas de maior importância são o melão ( $C$. melo $L_{.}$) e o pepino ( $C$. sativus $L_{.}$), enquanto que o cultivo do maxixe (C. anguria L.) ainda ë incipiente em nosso país. O maxixe é monóico, anual, de hábito de crescimento trepador ou prostrado, apresentando folhas lobadas, em contraste com as folhas tipicas do pepino e do melão (WHITAKER \& DAVIS, 1962; LOWER \& EDWARDS, 1986).

A origem do maxixe foi elucidada por MEEUSE 
Tabela 1 - Espécies de Cucumis, taxonomistas e nümero de cro mossomos (MALIICK \& MASUI, 1986)

\begin{tabular}{|c|c|c|c|c|}
\hline NO & Espe & $8 j e$ & $\begin{array}{c}\text { Iaxono } \\
\text { mista }\end{array}$ & $\begin{array}{l}\text { Cromos- } \\
\left(\begin{array}{l}2 \mathrm{n}) \\
\end{array}\right.\end{array}$ \\
\hline 1 & Cucumis & africanus & $I$. & 24 \\
\hline 2 & Cucumis & angorensis & Hook.f.ex.Cogn. & 24 \\
\hline 3 & Cucumis & angutia var. anguria & I. & 24 \\
\hline 4 & Cucumis & anguila var. longipes & L.Hook. A. Meeuse & 24 \\
\hline 5 & Cucumes & asper & $\operatorname{Cog} n$ & 24 \\
\hline 6 & Cucumis & callosus & Rottl. & 24 \\
\hline 7 & Cucumis & dinteri & $\operatorname{Cog} n$ & 24 \\
\hline 8 & Cucumis & dipsaceus & Ehrenb. & 24 \\
\hline 9 & Cucumis & bicifolius & A. Rich. & 48 \\
\hline 10 & Cucumis & bigarei & Dex.et.Naud. & 24 \\
\hline 11 & Cucumis & hardwickie & Royl. & 14 \\
\hline 12 & Cucumis & heptadacteles & Naud. & 48 \\
\hline 13 & Cucumis & humioructus & Stent. & 24 \\
\hline 14 & cucumis & hirsutus & Sond. & 24 \\
\hline 15 & Cucumis & hookeri & Naud. & 24 \\
\hline 16 & Cucumis & leptodermis. & Schweik. & $2 \dot{4}$ \\
\hline 17 & Cucumis & longipes & Hook & 24 \\
\hline 18 & Cucumis & melo & Is. & 24 \\
\hline 19 & Cucumis & metuliferus & E.Mey.ex.Schrad & 24 \\
\hline 20 & Cucumis & microcarpus & Naud. & 24 \\
\hline 21 & Cucumis & meriocarpus & Naud. & 24 \\
\hline 22 & Cucumis & prophetarum & Tacq. & 24 \\
\hline 23 & Cucumis & pubescens & Willd. & $2 \dot{4}$ \\
\hline 24 & Cucumis & pusturatus & Hook. $f$. & 48 \\
\hline 25 & Cucumis & sagittatus & Peyr. & 24 \\
\hline 26 & Cucumis & sativus & L. & 14 \\
\hline 27 & Cucumis & sativus var. analicus & Bail. & 14 \\
\hline 28 & Cucumis & sativus var. hatuditic & Kitam. & 14 \\
\hline 29 & Cucumis & saxivus var. sikkimensis & Hook.f. & 14 \\
\hline 30 & Cucumis & trigonus & Roxb. & 24 \\
\hline 31 & Cucumis & turbinatus & Roxb. & 24 \\
\hline 32 & Cucumis & zeyheri & Sona. & 24 \\
\hline
\end{tabular}


(1958). Através de estudos de compatibilidade e anälises eletroforéticas o autor concluiu que C. anguria L., com frutos não amargos, ê descendente de C. longipes HOOK. F., e propõe a nova denominação C. anguria L. var. anguria e C. angursa I. var. longipes MEEUSE, respectivamente.

As espëcies selvagens do Grupo Africano são relatadas por ESQUINAS-ALCAZAR \& GULLICK (1983). Algumas são utilizadas como ornamentais, como $C$. dipsaceus e $C$. metuliferus. A principal característica agronômica destevorä vel das espécies selvagens de Cucumis é a presença da cucur bitacina, composto de terpenóides que confere sabor amargo aos frutos e em partes vegetativas. O estudo da herança da cucurbitacina foi realizado por BARHAN (1953), demonstrando que o princípio amargo apresenta herança simples. O simbolo Bt foi proposto pelo autor para designar o gen dominante responsävel pela presença do princípio amargo, sendo que o alelo recessivo bt determina não amargor.

$$
\text { No entanto, estas espécies selvagens repre - }
$$
sentam um vasto potencial de recursos genéticos a ser utili zado no melhoramento de espécies cultivadas de cucumis, visando à incorporação de características de resistência a doenças e pragas presentes ao material selvagem ou à amplificação da variabilidade genëtica de populações cultivacias. 
2.1.2. Fontes de resistência a doenças e pragas

Segundo KHROON et alie (1979), pescuisadores do IVT mostram que $C$. a fricanus $L$. C. ficifolius A. RICH. e C. myriocarpus NAU, carregam resistência ao mosaico do pepino (CGMV), e que $C$. anguria I., C. ficifolius A. RICH. e C. metuliferus E. MEY. possivelmente säo resistentes a nematōides.

A herança do "cucumber green mottle mosaic virus" (CGMV) em Cucumis anguria I. foi determinada por NIJS (1982), através do cruzamento entre C. anguiia resis tente com C. myriocarpus suscetivel. Embora tenha ocorrido pequena distorção na segregação devido ao cruzamento interespecífico, ficou caracterizado o padrão de herança monogê... nica. Um gen dominante conferiu resistência ao CGMV, em $C$. anguria, o qual foi simbolizado por Cgm.

Oito espécies de Cucumis da coleção de germo plasma da França foram testadas por PITRAT \& VAULX (1979) para reação à infestação natural ou artificial dos princj pais patógenos: mosaico do pepino (CMV), mosaico da melan cia (WMV-2), míldio, Pyrenochaeta sp. e nematóides (Meloydogine incognital. Todas as espēcies foram suscetiveis a CMV e WMV-2, mas com diferentes nïveis de sensibilidade. Re sistência a míldio foi encontrada em $C$ dipsaceus, C. metilifferus e c. ficifolius, enquanto que somente c. metuliberus foi resistente a nematóides. 
Resistência ao äcaro rajado (Tetranychus unticae KOCH) foi encontrada pox PONTI (1978) em C.africanus, I., C. anguria L. e C. megriocarpus NAUL.

ESQUINAS-ALCAZAR \& CULICK (1983) relatam que resistência à mosca-branca (Trialeurodes vaporariorum (WESTw) é encontrada em $C$. asper COGN., C. dinteri COGN., C. dipsaceus SPACH e C. sagittatus PEXR.

GRANBERRY \& NORTON (1980) obtiveram híbridos entre uma linhagem selvagem de melão nativa do Texas, PI 140471, e C. metuliferus E. MEY PI 292190 para avaliação da reação de resistência a nematóides lMeloydogine incognita acrita). A progênie resultante apresentou plantas resistentes que produziram significativamente menos ovos que plantas susceptiveis, representando alto potencial ao desenvolvimenm to de cultivares de melão resistentes a nematóides.

Segundo GARCIA-SOB̧o et alii (1986), reação de resistência ao ácaro rajado, nematóides e CGMV vêm sendo des critas em Cucumis anguria L. var. longipes MEEUSE.

\subsection{Hibridação interespecífica}

\subsubsection{Considerações gerais}

A hibridação interespecifica vem sendo uma li nha fundamental de pesquisa de grande valor no melhoramento 
de plantas, e a literatura referente a cruzamentos amplos em programas de melhoramento vem se tornando volumosa. Uma justificativa para esse fato é que espëcies selvagens relacionạ das e progenitores de espëcies cultivadas possuem caracterís ticas adaptativas de interesse (BATES \& DEYOrE, 1973), Ou que espécies semi-selvagens representam um vasto potencial de recursos de variabilidade a ser explorado pelos melhoristas (DEAKIN, 1971).

HADLEY \& OPENSHAW (1980) afirmam que para se obter hỉbridos interespecíficos deve-se utilizar um ou mais dos procedimentos: 1. reunir uma coleção de cultivares repre sentativa e geneticamente contrastante (germoplasma); 2. proporcionar condições ambientais favoráveis ao florescimen-to; 3. testar värias combinações parentais, executando jnclu sive cruzanentos recíprocos; 4. mistura de pólen; 5. aplicax reguladores de crescjmento ou promover a germinação de pô-.. len; 6. fazer enxertia de garfagem; 7. provocar cortes no pistilo; 8. aumentar o nível de ploidia dos pais antes do cruzamento; 9. utilizar a técnica de cultura de embrião $F_{I}$ 10. fusão de protoplastos.

Segundo STALKER (1980), a utilização de espëcies selvagens no melhoramento da espécie cultivada depende da relação de compatibilidade entre as espécies, do modo de reprodução, nümero de genes controlando o caráter, métodos para superar grupos de ligação destavoráveis, facilidade em 
métodos de seleção e da quantidade de trabalho que pode ser dispendida no programa.

Briggs \& Knowles (1967, citados por HADLFYY

\& OPENSHAW (1980), relacionam as seguintes finalidades da hibridação interespecífica: a) para transferir um ou poucos genes de uma espëcie para outra; b) para conseguir nova expressão do caráter, não encontrada em cada pai; c) para produção de novas espécies alopoliplóides; d) para determinar o relacionamento interespecífico dentro de determinado gênero.

Segundo ALIARD (1971), a primeira preocupação num programa de melhoramento envolvendo hibridação inter específica é se uma planta viável $F_{1}$. pode ou não ser obtida. Ne-nhuma maneira de sabê-lo antecipadarnente foi até hoje descoberta. No geral, o grau de parentesco indicado pela posição taxonômica é o critêrio mais ütil para orientar o cruzamento, mas esta correlação está longe de ser perfeita.

Os hîbridos interespecíficos mostram toda uma gama de variação, cesde completa fertilidade até completa esterilidade. As possibilidades no melhoramento dos hibridos que produzem, mesmo ocasionalmente, uma descendência são, sem dưvida, inteiramente diferentes das possibilidades daqueles completamente estêreis.

Barreiras para o cruzamento interespecifico que atuam prevenindo o crescimento de híbridos $F_{1}$ são muito comuns em plantas (STEBBINS, 1958; STALKER, 1980; ALIARD, 1971). 
As causas de fxagilidade ou esterilidade do híbrido são numerosas, tendo suas bases em certo desequilibrio genëtico, podendo ser agrupadas em 3 categorias, de acordo com STEBBINS (1958):

a) a desarmonia pode residir inteiramente na incompatiblidade entre os genes e os cromossomos das 2 es pécies paternais, combinados no nücleo hỉbrido;

b) poderá haver uma interação não-harmônica entre os cromossomos ou genes de uma espëcie no citoplasma da outra;

c) o embrião hỉbrido pode ser perfeitamente capaz de se desenvolver às expensas de sua pröpria constituj Ção, mas pode ser inibido pela jucompatibilidade do endospeis ma que o circunda.

WHTTAKER \& DAVTS (1962) afirmam que as maiores possibilidades de êxito nos cruzamentos interespecíficos ocorrem quando as espécies cruzadas são provenientes de centros de origem mais pröxinos.

HARLAN (1976) ressalta que no futuro a necessidade de variabilidade genética e de fontes de resistência conduzirá à exploração de todos os recursos genéticcos disponîveis.

Há grande interesse na produção de hỉbridos interespecificos em Cucumis para transfexência de resistência a doenças e pragas, tolerância à seca e a baixas tempera turas (ESQUINAS-AICARAR \& GULIICK, 1983). 
2.2.2. Hübridação e relacionamento entre espécies de cucumis

o primeiro registro de êxito em cruzamentos interespecíficos no gênero cucumis foi reportado por MEEUSE (1958) utilizando C. longipes e C. anguria e postulando a origem do maxixe cultivado. Logo após, Naudin (1959), citado por DEAKIN et alii (1971), não teve sucesso na obtenção do produto do cruzamento entre C. melo e C. myriocarpus.

Andrus \& Fassuoliotis (1965), também citados por DEAKIN et alii (1971), obtiveram 13 híbridos interespecí ficos, oito dos quais com C. anguria e constataram que cruza mentos com $C$. melo e $C$. sativus não produziam progênie viăvel.

Cruzamentos entre espécies dos grupos africano e asiätico não apresentam resultados satisfatörios (KROon, 1979; KHO et alii, 1981; DEAKIN et alii, 1971; CUSTERS et alii, 1986). Segundo WHITAKER \& DAVIS (1962), cruzamentos dentrọ do grupo com número básico de cromossomos $\mathrm{x}=7$ sempre têm sucesso e dentro do grupo com $x=12$ a hibridação frequentemente é possível.

C. sativus e $C$. hardwickii cruzam normalnente entre si nos dois sentidos, produzindo frutos e sementes, mas não são relacionados com C. melo ou C. anguria nem com as espécies selvagens oriundas da đifrica (LOWER \& EDWARDS, 1986). 
Entre C. melo e C. sativus estudos de hibrida ção têm mostrado resultados negativos (BATHA, 1954; NIEMROWICZ-SZCYTT, 1976). NIEMROWICZ-SZCYTT (1976) relatam que após a polinização, a germinação e o crescimento do tubo polínico são frequentemente normais, podendo haver até fertì lização e desenvolvimento embrionáxio até o estágio globulax, mas o embrião não se desenvolve nem em meio de cultura a par tir desse estágio globular.

As espécies do Grupo Africano de Cucumis vềm sendo utilizadas com maior êxito em cruzamentos interespecíficos.

O estudo mais completo de hibridação interespecifico em Cucumis foi feito por DEAKIN, BOHN e WHITAKER (1971), utilizando 16 espécies inclusive o melão, o pepino e o maxixe. Os autores apresentam descrições detalhadas e foto grafias das espécies bem como dos híbridos obtidos. Estudos de morfologia, fisiologia e compatibilidade são combinados com uma interpretação filogenética das espécies de cucumis em questão. Os autores apresentaram os resultados divididos por espécies, sendo apresentados a seguir aqueles relativos às espécies utilizadas no presente trabalho.

a) Cucumis africanus

C. africanus cruzou facilmente com C. anguria vars. anguria e longipes; também com C. dipsaceus, C. leptodermis, C. myriocarpus, C. prophetarum e C. jicifolius. 
cruzamento entre C. africanus e C. anguria rendeu híbridos vigorosos, verde normal e prolíficos quando C. anguria foi usada como fêmea, mas o cruzamento recíproco rendeu poucas sementes viáveis que produziram plântulas fracas e de cor verde-clara.

b) C. anguria var. anguria e C. anguria var. longipes.

C. anguria var, anguria cruzou facilmente com c. anguria var. longipes, produzindo híbridos férteis e vigorosos, com sementes abundantes provenientes de flores auto fecundadas.

C. anguria vars. anguria e longipes ainda puderam ser cruzados com C. dipsaceus, C. africanus, C. Leptodermis, C. myriocarpus, C. bicifolius, C. prophetarum e C. zewheri, rendendo hỉbridos parcialmente férteis.

\section{c) C. dipsaceus}

Além de cruzar com C. anguria, C. dipsaceus produziu frutos e sementes provenientes de cruzamentos com C. Africanus, C. ficifolius e C. zeyheri. Houve produção de frutos sem sementes com C. leptodermis, C. myriocarpus, C. melo e C. prophetarum.

d) C. metuliferus

C. metuliferus não produziu frutos e semen tes em cruzamentos com as 15 espécies de Cucumis utilizadas. 
e) C. ficifolius

Produziu hî̉bridos auto-estéreis quando

cruzado com C. africanus, C. anguria, C. zegheri e C. dipsaceus, sendo os três últimos parcialmente férteis em cru zamentos. Contagens de cromossomos indicaram que os três pri meiros hîbridos foram triplöides.

f) C. myriocarpus

C. myriocarpus cruzou com C. anguria e C. afri canus, produzindo híbridos pouco férteis.

ROBINSON \& KOWALEWSKI·(1978) realizaram um dialélico recíproco entre pepino, melão, maxixe e 13 espécies selvagens de Cucumis. Não foram obtidos frutos em nenhum cruzamento entre pepino e as espécies selvagens, e entre melão e apenas duas espécies, C. callosus e C. trigonus, - foram obtidos frutos partenocárpicos. O maxixe, no entanto, produziu hỉbridos férteis quando cruzado com c. hookeri, $c$. leptodermis, C. zeyheri e C. longipes.

NIJS et alii (1981) estudaram o comportamento em cruzamentos de 3 espécies: C. africanus L.E., C. myrig carpus NAUD e C. anguria L. Os três cruzamentos interespecíficos originaram sementes que germinavam, mas as plântulas morriam após cerca de 4 semanas de crescimento. Segundo os autores, este è um caso especial de inviabilidade do híbrido, e a morte das plântulas dependia da introdução usada no cru- 
zamento. Na hibridação entre C. africanus e C. anguria apenas algumas combinações tiveram sucesso, correspondendo, segundo os autores, a variabilidade para capacidade de cruza mento. O cruzamento entre C. africanus e C. myriocarpus foi menos promissor: houve germinação parcial de sementes, mas todos os "seedlings" morreram. C. myriocarpus e C. anguria produziram frutos sem sementes, mas o reciproco originou pro gênies vigorosas em vārias combinações. Para superar a morte de "seedlings" os autores utilizaram técnicas de cultura de tecido e enxertia, mas não tiveram resultados promissores, concluindo que o sucesso em cruzamentos interespecíficos depende das introduções usadas por diferentes pesquisadores.

OOST \& NIJS (1979) utilizaram tëcnica especial denominada" Técnica do Pölen Mentor" para superar barrei ras de cruzamento entre C. metuliferus, C. africanus e C. sa tivus, visando a introduzir resistência a Meloidogyne spp. e CGMV no pepino.

A técnica do "Pólen Mentor" para superar barreiras entre espécies aparentadas foi usada com sucesso por STETTLER (1968), citado por NIJS \& OOST (1980), no gênero Populus. O autor usou o termo "Mentor" ao pólen da fêmea, considerado geneticamente inativo por altas doses de radiação, porém, fisiologicamente capaz de germinar e ter o crescimento do tubo polínico, mas não havendo fertilização. o pō len do progenitor masculino é misturado ao pólen irradiado 
e a seguir são feitas as polinizaçöes desejadas. Segundo o autor, a técnica de mistura de pólen supera a incompatibilí dade a nível de estigma, permitindo a fertilização de nature za interespecífica.

OOST \& NIJS (1979), através dessa técnica, obtiveram frutos resultantes de cruzamento entre c. metulife rus e c. africanus com algumas sementes, mas constataram degeneração do embrião.

Posteriormente, NIJS et alii (1980) utiliza ram a técnica do "Pólen Mentor" juntamente com aplicação de AVG (amino-etóxi-vinil-glicina) na flor feminina após polinị zação e cultura de embrião. Houve produção de frutos e sementes no cruzamento entre c. africanus e C. metuliferus e no reciproco, mas em cultura de embrião apenas $c$. metulife rus $x$ C. africanus originaram plântulas, cuja natureza híbrida foi confirmada por eletroforese. Estes resultados foram confirmados por CUSTERS et alii (1981), que tambēm estudaram a eficiência das técnicas de auxỉlio à polinização descritas.

CUSTERS \& VAN (1980) avaliaram o desenvolvimento dos embriões hỉbridos entre as espécies $C$. metuliferus e c. africanus, "in vivo" e "in vitro", verificando que ape nas os maiores embriões originaram plântulas hỉbridas normais.

NIJS \& OOST (1.980) não tiveram sucesso 
com a utilização do "pölen Mentor", em cruzamentos entre $C$. metuliferus e C. africanus. Foram obtidos frutos e sementes em todos os casos em que o "Pólen Mentor" foi usado, mas as sementes não continham embrião. F́oram observadas sementes com saco embrionário desenvolvido e estruturas semelhantes a embriões, que no entanto quando transplantadas para meio de cultura não se desenvolveram.

KHO, NIJS \& FRANKEN (1980a) estudaram a viabilidade de cruzamento de 12 espécies de Cucumis em dialëlico, examinando o crescimento do tubo polínico e avaliando a produção de frutos e sementes. As sementes obtidas dos cruzamen tos interespecíficos produziram plantas $F_{I}$ que foram julga das para características híbridas e de fertilidade. O compor tamento do tubo polinico em cruzamentos entre espëcies do grupo africano originou uma classificação dessas espécies em três grupos distintos:

18) Compatibilidade bilateral: o tubo polinico atinge os óvulos em cruzamentos recíprocos. Ocorreu em cruzamentos entre: C. a fricanus, C. dipsaceus, C. figarei (exceto C. africanus e C. figarei) e C. anguria;

2.) Incompatibilidade bilateral: observada em todos os cruzamentos envolvendo C. metuliferus e C. melo;

38) Incompatibilidade unilateral: o tubo poli nico atinge o óvulo em apenas uma direção de cruzamento. 
Foi encontrada em muitos cruzamentos com C. ficifolius. \& C. prophetarum e C. muriocarpus. C. ficifolius e c. africanus produziram frutos e sementes em cruzamentos com espécies africanas, enquanto que C. prophetarum e C. myriocarpus comportaram-se melhor como polinizadores. Não houve produçăo de sementes em cruzamentos entre espécies do Grupo Africano e C. sativus e também entre espécies africanas e C. melo. Segundo os autores, a produção de sementes nem sempre concordou com observações do crescimento do tubo polínico.

KHO, NIJS \& FRANKEN (1980b) também estudaram o crescimento do tubo polínico em um dialélico envolvendo Io espécies de Cucumis, identificando barreiras ao crescimento do tubo polínico no estigma, estilete e ovārio.

NIJS \& VISSER (1.985) estimaram relações de compatibilidade entre 9 espécies de Cucumis através da produção, vigor e fertilidade de 29 híbridos obtidos das 72 combinações possíveis. A produção e estabilidade do pólen bem como a produção de frutos e sementes foram avaliadas apōs auto-fecundações dos híbridos interespecíficos e retrocruzamentos com as espécies parentais. A forma do fruto dos hỉbri dos foi sempre intermediäria entre a forma das espécies parentais. A partir dos resultados obtidos, os autores propõem uma classificação taxonômica às espécies do gênero cucumis.

Segundo NORTON \& GRANBERRY (1980), estudos 
da progênie resultante do cruzamento entre C. melo PI 140471 x C. metulibenus E. Mey PI 292190 através de caracteristicas de folha, fruto, espiculosidade, pölen e sementes, confirmaram sua natureza hibrida. 


\section{MATERTAL E METODO}

\subsection{Locais de investigaçäo} .

o presente trabalho foi realizado em condi ções de casa de vegetação e de campo nas instalações do nepartamento de Genética da Escola Superior de Agricultura "Luiz de Queiroz", da Universidade de São Paulo (ESALQ/USP), em Piracicaba, SP, no periodo de março a dezembro de 1986 , sendo concluído em condições de campo do Departamento de Agronomia da Universidade Estadual Paulista "Júlio de Mesquita Filho" (UNESP), Campus de Ilha Solteira, sP, em agosto de 1987.

\subsection{MateriaI}

As espécies de Cucumis utilizadas no presente estudo pertencem à coleção de germoplasma do setor de Melho ramento de Hortaliças do Departamento de Genética da ESALQ/ USP, e são apresentadas na I'abela 2 . 
Tabela 2 - Espécie, designação e procedência das introduções de Cucumis utilizadas na hibridação interespecífica. Piracicaba, SP, 1986.

\begin{tabular}{|c|c|c|c|}
\hline NO & Espécie & Designação & Procedência \\
\hline 01 & C. africanus L. $\mathrm{f}$. & - & África do Sul \\
\hline 02 & C. dipsaceus SPACH. & GBNR 1733 & Etiōpia \\
\hline 03 & c. dipsaceus SёAсH. & GBNR 1774 & Etiōpia \\
\hline 04 & C. ficifoliusA.RICH & PI 223646 & Etiōpia \\
\hline 05 & c. longipes HoOR.f. & PI 249396 & Árica \\
\hline 06 & C. longipes HOOK.f. & - & África do sul \\
\hline 07 & c. metuliferus NAUD. & - & Japão \\
\hline 08 & c. myriocarpus NAUD. & PI 282449 & África do sul \\
\hline 09 & C. myriocarpus NAUD. & PI 374153 & E.U.A. \\
\hline 10 & C. anguria L. & $\mathrm{BGH} 4146 /\left(\mathrm{Mx} 23-\mathrm{I}_{2}\right)^{(\mathrm{a})}$ & Santa Tereza - ES. \\
\hline 11 & C. anguria L. & $\operatorname{Mx} 6-77^{(a)}$ & Montes Claros - MG. \\
\hline 12 & C. anguria $\mathrm{L}$. & Composto carambola & Piracicaba \\
\hline 13 & C. anguria L. & PI 91676 & E.U.A. \\
\hline 14 & C. anguria L. & $\operatorname{Mx} 41-1(a)$ & Dourados - MS \\
\hline 15 & C. anguria $\mathrm{L}$. & $\operatorname{Mx} 22^{(a)}$ & África do sul \\
\hline
\end{tabular}

(a) : Código de introdução da coleção de germoplasma de cucü. mis do Departamento de Genética, ESALQ/USP. 


\subsection{Metodo}

\subsubsection{Procedimento de obtenção de mudas}

A semeadura f $\bullet$ feita em Placas de Petri contendo uma camada de vermiculita e papel de filtro umedecido. As Placas de Petri foram então mantidas em germinador stultz de temperatura alternada $\left(20^{\circ} \mathrm{C}\right.$ durante $16 \mathrm{~h}$ e $30^{\circ} \mathrm{C}$ durante $8 \mathrm{~h}$ ), no escuro (FRATIN, informação pessoal), "até emissão da radicula. Este procedimento teve por objetivo reduzir a amplitude do perỉodo de germinação e superar a dormência de se mentes que ocorre nas espécies do cucumis utilizadas.

As sementes pré-germinadas foram transferidas para bandejas de isopor, onde foram mantidas atë as mudas desenvolverem 3 a 4 folhas verdadeiras, sendo posteriormente levadas ao campo ou à casa de vegetação.

\subsubsection{Tratos culturais}

Nos experimentos de campo os tratos culturais seguiram a necessidade e os procedimentos normais utilizadas para a cultura do maxixe no Departamento de Genëtica da ESALQ/USP.

Durante todo o ciclo da cultura procedeu - se à irrigação por infiltração em sulcos, quando necessāria. 


\subsubsection{Hibridaço interespeoricica}

As mudas obtidas de acordo com o item 3.3.1. foram transplantadas em canteiros em casa de vegetação, para poupar mão-de-obra na proteção das flores femininas antes da antese e garantir a ausência de contaminação por pólen estranho, considerando-se que no gênero cucumis a poliniza ção é aberta e entomófila.

Os cruzamentos foram feitos entre as espëcies

selvagens e entre as espēcies selvagens e o maxixe (C. angü rial, em ambas as direções. Alẻm. disso, foram efetuadas auto fecundações de todas as espëcies progenitoras. A Tabela 3 apresenta os cruzamentos realizados.

Tabela 3 - Cruzamentos realizädos. Nas linhas aparecem espé cies utilizadas como progenitor feminino; nas colunas, espécies utilizadas como progenitor mascuIino. Piracicaba, SP, 1986.

\begin{tabular}{|c|c|c|c|c|c|c|c|}
\hline & 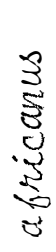 & 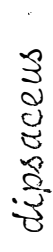 & 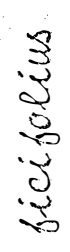 & 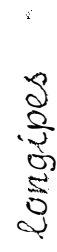 & 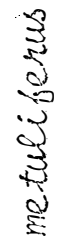 & 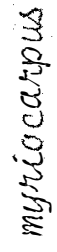 & $\begin{array}{l}3 \\
3 \\
3 \\
3 \\
3 \\
3\end{array}$ \\
\hline & $ن^{\circ}$ & $\dot{u}^{\circ}$ & $\dot{v}$ & $\dot{0}$ & $\dot{0}$ & $\dot{j}$ & j \\
\hline c. africanus & $\chi$ & & $x$ & $x$ & $x$ & $x$ & $x$ \\
\hline c. dipsaceus & $x$ & $\chi$ & & & & & \\
\hline c. ficilolius & & $\chi$ & & $x$ & & & \\
\hline C. longipes & $\chi$ & & · & $x$ & $\chi$ & $\chi$ & $x$ \\
\hline c. metuliferus & & & & & $x$ & & \\
\hline c. myriocarpus & & & & & $\chi$ & $\chi$ & $\chi$ \\
\hline C. anguria & $\chi$ & $x$ & $x$ & $x$ & $x$ & $\chi$ & $x$ \\
\hline
\end{tabular}


As flores foram polinizadas no estádio de antese, período em que o estigma apresenta maior receptividade, pela manhã, a partir das 8 ou 9 horas.

Realizaram-se värias etapas de cruzamentos interespecíficos, a partir de março de 1986, sendo os dă dos tomados conjuntamente na determinação da compatibili dade em termos de frutificação.

As plantas $F_{1}$ interespecificas foram avalia das para viabilidade, caracteristicas de folha, fruto, es pinhos e resistência a doenças, em relação aos pais. Posteriormente, foram realizadas auto-ecundações dos hỉbri C̈os interespecíficos cujo progenitor feminino era C. anguria para se verificar a fertilidade e possibilidade de obtenção de gerações $F_{2}$ e retrocruzarnentos para o maxixe, em condições de campo. As mudas foram obtidas segundo

3.3.1. e transplantadas ao campo. o procedimento de auto i̇ecundação e retrocruzamentos consistiu de proteção da flor feminina no dia anterior à antese, efetuando-se as polinizações desejadas no dia seguinte pela manhã. A r Ior polinizada era então protegida com sacos de papel contendo perfurações, para evitar contaminaçöes e permitir trocas gasosas.

A avaliação da compatibilidade de cruzamen to na hibridação interespecífica, auto-fecundação das espëcies progenitoras e hibridos e em retrocruzamentos pa 
ra c. anguria foj expressa pelos seguintes parâmetros:

a) Pegamento de Eruto - representa a porcentagem do numero de flores polinizadas convertj.das em frutos em relação ao nümero total de polinizações efetuadas.

k) Quantidade e qualidade das sementes - foram feitas observações de quantidade de sementes em relação à espécie cultivada c. anguria e da qualidade da semente proaiuzidar sendo considerada rudimentar a semente mal-formada e aquela contendo apenas o pericarpo ("casca"). Também foi verificada a presença de embrião e determina da a porcentagem de germinação de alguns hỉbridos interespeci ficos.

\subsubsection{Obtençäo das sementes}

Para obtenção de sementes $F_{1}$ interespecíficas $F_{2}$ ou resultantes de retrocruzamentos, os frutos foram com lhidos apos maturação completa, indicada pela coloração característica, aproximadamente um mês apōs a polinização, cortados e deizados para fermentar em copos plästicos durante 4 a 7 dias. A seguir, as sementes eram lavadas, eliminando-se a mucilagem, e colocadas para secar à sombra, sob temperatura ambiente, sendo posteriormente mantidas em câmara seca . 
3.3.5. Avaliação do potencial de produççăo de fxutos de alguns hỉbridos interespecificos no gênero cucumis

Foi realizado um ensaio preliminar para se avaliar o potencial de produção de alguns hỉbridos interespecificos de irteresse que constam na tabela 4 e de seus respectivos progenitores.

Em virtude da área experimental reduzida, foram avaliados somente os hibridos entre o maxixe e as esFécies selvagens $c$. a fricanus, C. Rongipes e C. nyriocarpus, que mostraram maior conpatibilidade com $C$. anguhia. O hïbrido resultante do cruzamento entre $c$. africanus $x$. myriocarpus foi incluido por apresentar grande vigor e prolificidade, caracteristicas que despertaram interesse.

Os hỉbridos e respectivos pais foram obtidos segundo o procedimento de obtenção de mudas (3.3.1.) e cultivados após transplante no campo em outubro de 1986 com espaçamento de $1 \mathrm{~m}$ entre linhas e 1 m entre plantas.

Poi utilizado o delineamento experimental de blocos ao acaso com 3 repetições e 5 plantas por parcela. Houve, no entanto, casos de parcelas com plantas mortas após o transplante e com plantas contaminantes correspondentes às espécies parentais, que foram arrancadas. 
Tabela 4 - Híbridos interespecificos e seus respectivos progenitores avaliados quanto ao potencial de produção. Piracicaba, S.P., 1986.

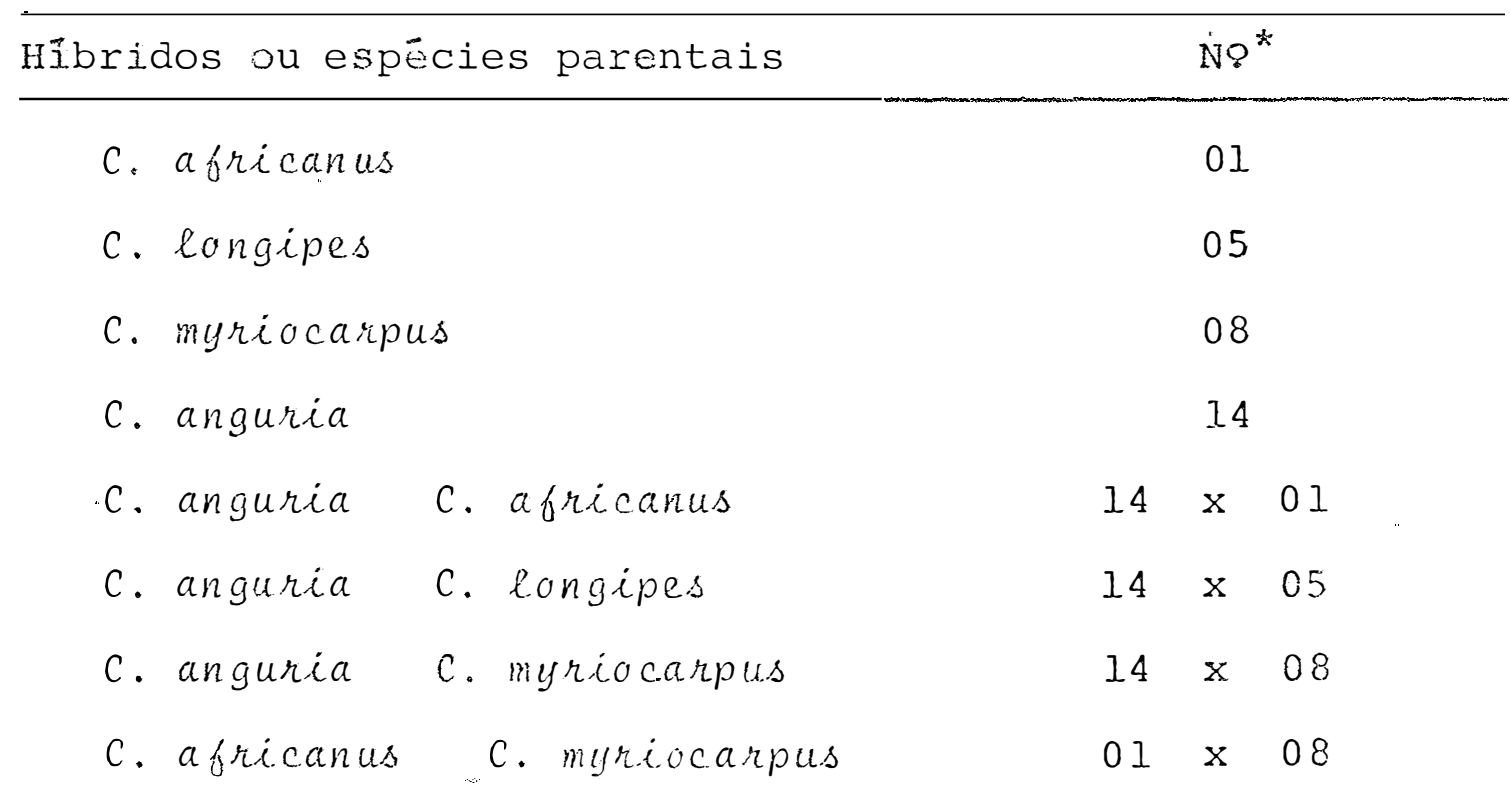

* Nümexo utilizado na hibridação interespeç̃fica (Tabela 2).

Assim sendo, foram utilizadas somente 3 plantas por parcela para obtenção dos dados experimentais.

Foram avaliados os seguintes parâmetros:

a) Nümero de frutos: correspondente ao nümero médio de frutos produzidos por parcela de $3 \mathrm{~m}^{2}$;

b) Rendimento de frutos: correspondente ao peso médio de frutos produzidos por parcela de $3 \mathrm{~m}^{2}$;

c) Diämetro do fruto: obtido atravês da mensu-ração da seção transversal do fruto e correspondente ao vaJor mëdio obtido da amostragem ao acaso de 5 frutos por 
parcela, por colheita;

e) Peso médio do fxuto: correspondente à médía do peso de 5 frutos colhidos ao acaso por parcela, ror com Iheita.

Foram efetuadas 5 colheitas com intervalos de uma semana a partir de novembro de 1986 . Depois disso, houve ataques severos de mosaico de melancia (WMV) e de poäridão gomosa do caule causada por Didymella bryoniae, que inviabilizaram a continuidade das colheitas.

A anảlise de variância dos dados seguiu a metodologia de STEEL \& TORRIE (1960), sendo o efeito de tra tamentos decomposto nos componentes: espécies, híbridos e grupos.

Os dados de nümero de frutos por parcela foram transformados em $\sqrt{\mathrm{x}}+0,5$, segundo procedimento indica do por STEEL \& TORRIE (1.960).

A comparação de médias entre os tratamentos foi feita pelo Teste de Tukey, segundo PIMENTEL GOMES (1976). 


\section{RESULTADOS E DISCUSSAOO}

\subsection{Hibridação interespecífica}

Os resultados da hibridação interespecífica expressos em pegamento de frutos e da obtenção de gerações $\mathrm{F}_{2}$ e de retrocruzamentos são apresentados nas Tabelas 4 a 20 .

As espécies selvagens de cucumis apresentaram grande diversidade quanto ao tipo, formato e tamanho de fruto. No aspecto vegetativo, c. ficifolius, c. africanus e C. myriocarpus apresentaram semelhanças a C. anguria principalmente no formato das folhas, que são lobadas com profundos recortes. Jä C. longipes, C. dipsaceus e C. metuliferus exibiram folhas semelhantes às do melão, com borcias sem recortes e formato redondo.

Grande prolificidade foi observada em C. myriocarpus, espécies que produz flores femininas em cächos e frutificam em cada nó, exceto naqueles que emitem ramos laterais. A espécie menos prolźfica foi C. africanus, com padrão de frutificação semelhante ao do maxixe, normalmente produzindo um único fruto no ramo lateral. Essas observa- 
vações coincidem com YOKOYAMA (1987).

As espëcies C. africanus, C. longipes e C. myriocarpus desenvolveram a primeira flor feminina cerca de 50 a 60 dias apös a semeadura, enquanto C. anguria a produziu cerca de 40 dias após a semeadura. C. bicifolius, C. díp saceus e C. metuliferus praticamente produziram somente flores masculinas, o que explica o reduzido nümero de cruzamentos utilizando essas espēcies como progenitor feminino. Foram feitas aplicações de Ethrell para tentar superar o pro blema, porēm, sem sucesso.

Em plantio realizado em outubro de 1986, obser vou-se severa incidência de mosaico da melancia (WMV) e da podridão gomosa das hastes (Didymella bryonial), sendo ģue C. africanus mostrou-se altamente resistente a ambos os pató genos. C. anguria e C. longipes foram as espécies mais sus-ceptíveis.

Não foram efetuados todos os cruzamentos interespecíficos, retrocruzamentos ou gerações $F_{2}$ devido a diversos problemas: a) não coincidência de florescimento entre as espëcies e ausência de flores Îemininas em alguns casos; b) incidência de virose em progenitores susceptîveis, como C. longipes e C. anguria e em alguns híbridos; c) ataque de pulgão, que embora controlado debilitou as plantas; d) temperatura elevada e ventos fortes, em Ilina solteira, que provocaram a morte de algumas plantas, principalmente 
após o transplante.

\subsubsection{Cruzamento de C. anguria x C. africanus}

C. anguria cruzou facilmente com C. africanus (Tabela 5), confirmando os resultados obtidos por DEAKIN et alii (1971), com espécies africanas. O pegamento de frutos foi relativamente alto, 64,0\%, concluindo-se que as espécies são proximamente relacionadas.

KHO et alii (1980b) relatan que também obtive ram híbridos entre essas espécies e verificaram que o tubo polínico alcança o óvulo em cruzamentos recíprocos, exceto para uma introdução de C. anguria. Segundo KHO, NIJS \& FRANKEN (1980a) ambas as espécies são incluídas no grupo onde ocorre compatiblidade bilateral, embora tenham observado uma introdução de $C$. anguria que produziu frutos sem sementes após cruzamento. Estes casos são exemplos de variação intraespecífica, que não ocorreu neste trabalho.

Os cruzamentos $13 \times 1$ e $15 \times 1$ produziram pequena quantidade de sementes, rudimentares, que não germinaram nas condiçöes estabelecidas, sendo verificado que as sementes não continham embrião.

No cruzamento recíproco (Tabela 6 ) houve baixo pegamento de frutos sendo que o cruzamento $1 \times 10$ não produziu frutos. As combinações $1 \times 13$ e 1 x 15 produziram 
Tabela 5 - Hibridação interespecifica de C. anguria x C. a hri canus, expressa em pegamento de frutos (c). Piracicaba, SP, 1986 .

\begin{tabular}{|c|c|c|c|c|c|}
\hline $\begin{array}{l}\text { Canbinaçäo } \\
\text { parental }\end{array}$ & $\begin{array}{c}\text { No de } \\
\text { polini zações }\end{array}$ & $\begin{array}{l}\text { No de } \\
\text { frutos }\end{array}$ & $\begin{array}{l}\text { Pegamento } \\
\text { de fruto (\%) }\end{array}$ & $\begin{array}{l}\text { Germinação } \\
\left(\frac{\circ}{0}\right)\end{array}$ & Coservação \\
\hline $10 \times 1$ & 4 & 2 & 50,0 & 20,0 & MS \\
\hline $11 \times 1$ & 7 & 5 & 71,4 & 53,3 & - \\
\hline $12 \times 1$ & 2 & 2 & 100,0 & 60,0 & PS \\
\hline $13 \times 1$ & 3 & 2 & 66,7 & 0 & $S R, \quad F E$ \\
\hline $14 \times 1$ & 2 & 1 & 50,0 & 86,7 & - \\
\hline $15 \times 1$ & 7 & 4 & 57,1 & 0 & $S R, \quad A E$ \\
\hline Geral & 25 & & 64,0 & & \\
\hline
\end{tabular}

MS : muita semente

$A E$ : ausência de embrião

PS: pouca semente

SR: semente rudimentar

Tabela 6 - Hibridação interespecífica de C. africanus x $C$. anguria, expressa em pegamento de frutos (\%)..Piracicaba, SP, 1.986 .

\begin{tabular}{ccccc}
\hline $\begin{array}{c}\text { Combinação } \\
\text { parental }\end{array}$ & $\begin{array}{c}\text { No de } \\
\text { polinizações }\end{array}$ & $\begin{array}{c}\text { No de } \\
\text { frutos }\end{array}$ & $\begin{array}{c}\text { Pegamento de fruto (\%) } \\
\text { d }\end{array}$ & Observação \\
\hline $1 \times 10$ & 3 & 0 & 0 & - \\
$1 \times 13$ & 4 & 1 & 25 & PS \\
$1 \times 15$ & 4 & 1 & 25 & PS \\
\hline Geral & 11 & & 18,1 & \\
\hline
\end{tabular}

PS: pouca semente 
poucas sementes viāveis, sendo que o híbrido $l \times 15$ se desenvolveu pouco e não atingiu a maturidade. Este resultado concorda com o de NIJS (1981), que observou a morte de plân tulas em certas combinações de C. africanus $\mathrm{x} C$. anguria, considerada como debilidade do hủbrido.

Os dados mostram que C. africanus se comporta melhor como progenitox masculino em cruzamentos com C. anguria, confirmando a conclusão de DEAKIN (1971). Ressalta-se, portanto, que as mesmas conclusões descritas por DEAKIN(1971) a partir de hibridações entre as espécies $C$. anguria $x \quad C$. africanus nativas da $\overline{\text { ffrica }}$ foram constatadas utilizando -se introduções brasileiras de C. anguria.

Dá Tabela 7 podemos considerar viável a obten ção de geraçöes $F_{2}$ a partir do hỉbrido interespecífico c.anguria $\mathrm{x}$ C. africanus, embora com menor indice de pegamento de frutos $(37,5 \%)$.

Foi verificada a natureza híbrida de todas as combinações obtidas, através de diferenças fenotípicas de caracteristicas de frutos entre os hỉbridos e os respectivos progenitores. Os cruzamentos entre maxixe liso e C. africa nus foram particularmente interessantes, pois o hỉbrido exibiu frutos altamente espiculosos, com espinhos maiores, porêm, menos agressivos que os do progenitor selvagem (Foto 1 ).

Segundo YoKOYAMA (1987), o caráter espiculosi 


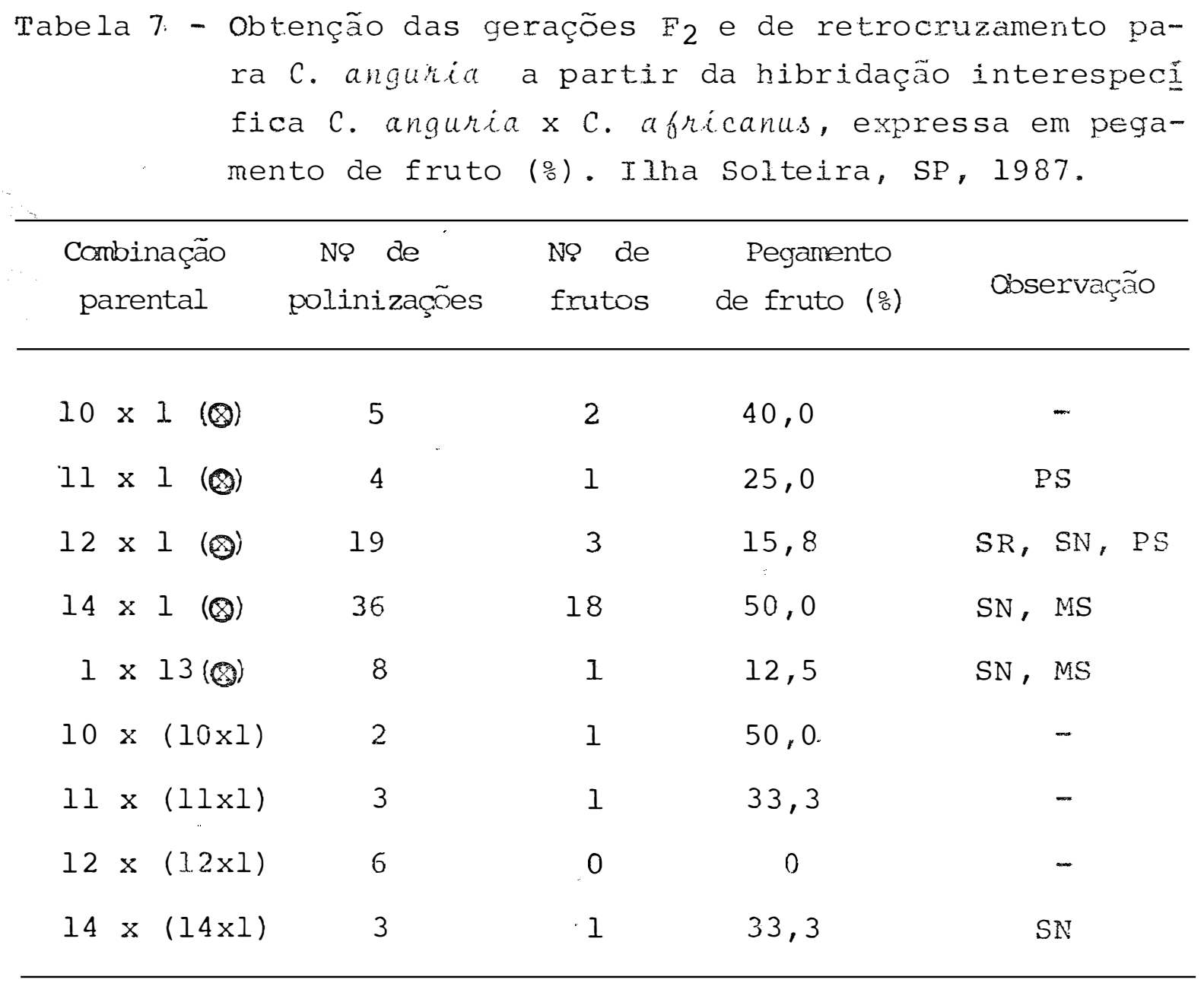

PS: pouca semente

MS: muita semente

$\mathrm{SN}$ : semente normal

$\mathrm{SR}$ : semente rudimentar 


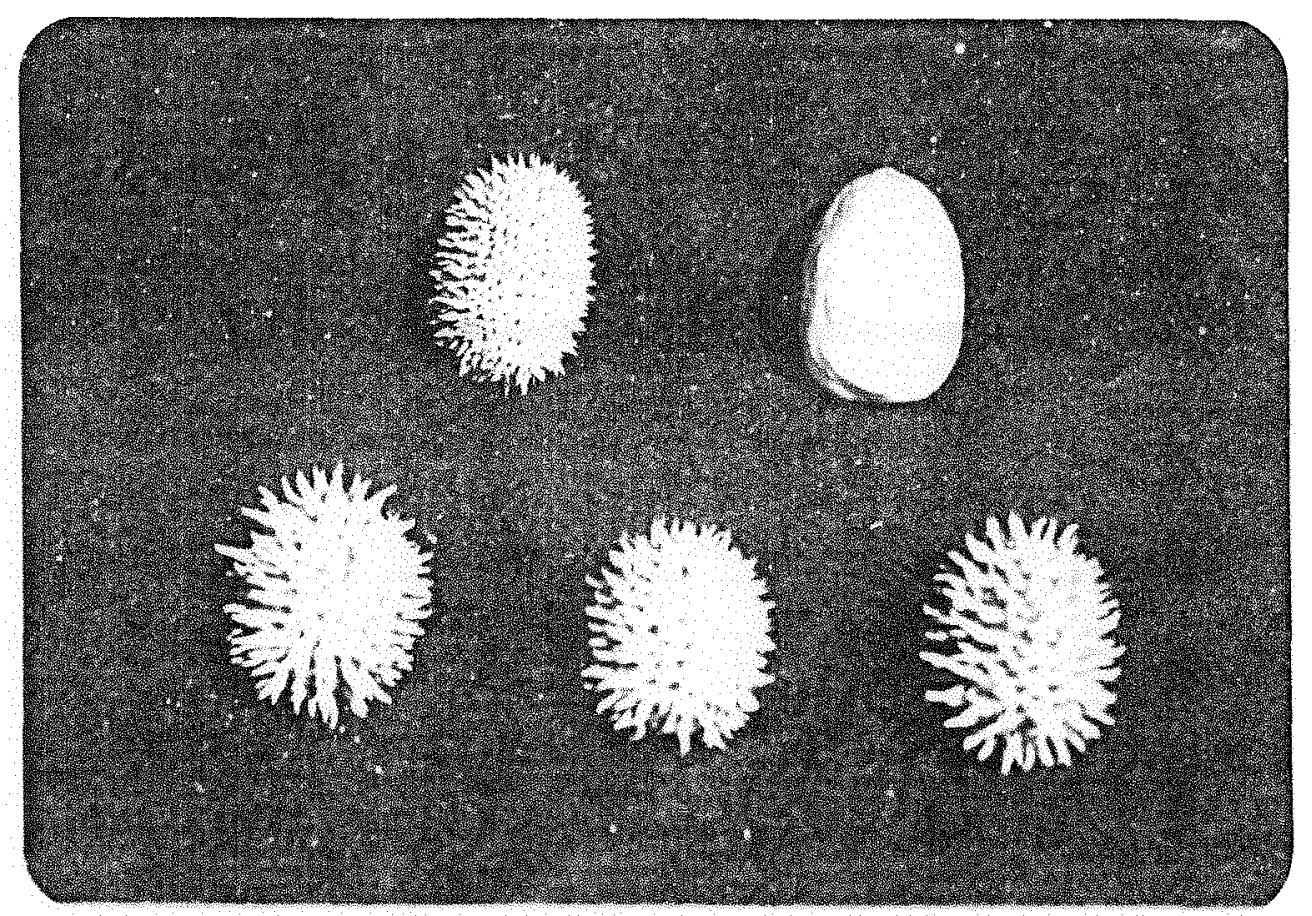

Foto 1 - Na parte superior: C. africanus (à esquerda) e C. anguria (à direita); na parte inferior: híbridos $F_{1}$ interespecíficos

dade de frutos em C. anguria L. é governado por dois pares de genes dominantes.

\section{Os híbridos $12 \times 1$ e $14 \times 1$ foram bastante} prolíficos e produziram flores femininas em abundância, o que explica o grande nümero de auto-fecundações efetuadas.

Em todos os híbridos houve persistência de frutificação mesmo havendo frutos em estāgio adiantado de produção de sementes.

Pela Tabela 7 podemos ainda concluir que os retrocruzamentos para C. anguria são viáveis, exceto para $12 \times(12 \times 1)$, obtendo-se bom pegamento de frutos e sementes normais. DEAKIN et alii (1971) relatam a possibilidade de oḅ tenção de gerações de retrocruzamento, verificando que os 
frutos produziram cerca de 30 a $50 \%$ de sementes normais.

$$
\text { Este cruzamento interespecifico tem grande }
$$

potencial para exploração no melhoramento do maxixe, una vez que C. africanus carrega resistência ao mosaico da melancia (WMV) e do pepino (CGMV) (KROON et alii, 1949; OOST e NIJS, 1979; NIJS et alii, 1980). Realmente, os híbridos de C. anguria x C. africanus mostraram-se resistentes à infestação natural de WMV e também à podridão gomosa das hastes causada por D. bryoniae.

\subsubsection{Cruzamento de $C$. anguria $\times$ C. dipsaceus}

Pela Tabela 8 pode-se observar que não houve sucesso no cruzamento dessas duas espécies. As combinaçōes $11 \times 2$ e 11 × 3 não produziram frutos; jā $10 \times 3$ e 14 x 3 produziram frutos sem semente ou com apenas uma semente, res pectivamente. Esta semente originou uma planta que morreu an tes do florescimento.

Sendo, assim, considera-se que não há possibilidade de cruzamento entre $C$. anguria e C. dipsaceus.

DEAKIN et alii (1971) obtiveram frutos parcialmente férteis entre $C$. anguria e $C$. dipsaceus e no reciproco, e NIJS (1980) relata boa produção de sementes nos mes 
Tabela 8 - Hibridação interespecifica de $C$. anguria $x$ C. die saceus expressa em pegamento de fruto (\%). Piraci caba, SP, 1986 .

\begin{tabular}{ccccc}
\hline $\begin{array}{c}\text { Combinaçäo } \\
\text { parental }\end{array}$ & $\begin{array}{c}\text { No de } \\
\text { polinizações }\end{array}$ & $\begin{array}{c}\text { No de } \\
\text { frutos }\end{array}$ & $\begin{array}{c}\text { Pegamento } \\
\text { de fruto }(\%)\end{array}$ & Observação \\
\hline $10 \times 3$ & 2 & 2 & 100 & FSS \\
$11 \times 2$ & 1 & 0 & 0 & - \\
$11 \times 3$ & 2 & 0 & 0 & $*$ \\
$14 \times 3$ & 2 & 1 & 50 & \\
\hline Geral & 7 & & 42,86 & \\
\hline
\end{tabular}

FSS: fruto sem semente

*: apenas uma semente

mos cruzamentos. Jä NIJS \& VISSER (1985) não identificaram híbridos entre $C$. anguria $\mathrm{x} C$. dipsaceus.

\subsubsection{Cruzamento de C. anguria x C. ficifoliug}

De acordo com a Tabela 9, C. anguria $\times$ C. ficifolius produziram hỉbridos em uma combinação parental (Foto 2). O híbrido $10 \times 4$ produziu sementes normais e em grande quantidade após auto-fecundação, o mesmo ocorrendo apỏs retrocruzamento para C. anguria no 10 (Tabela 10). Este fato causou estranheza, uma vez que segundo relatos da literatura a espëcie C. ficifolius é tetraplóide, produzindo híbridos estéreis após cruzamento com C. anguria (DEAKIN et alii, 1971; 
Tabela 9 - Hibridação interespecífica de C. anguria x C. jicifolius expressa em pegamento de fruto (은. Piracicaba, SP, 1986.

\begin{tabular}{cccccc}
\hline $\begin{array}{c}\text { Combinação } \\
\text { parental }\end{array}$ & $\begin{array}{c}\text { No de } \\
\text { polinizações }\end{array}$ & $\begin{array}{c}\text { No de } \\
\text { frutos }\end{array}$ & $\begin{array}{c}\text { Pegamento } \\
\text { de fruto } \\
\left(\frac{\circ}{0}\right)\end{array}$ & $\begin{array}{c}\text { Geminação } \\
\left(\frac{\circ}{\circ}\right)\end{array}$ & osservação \\
\hline $10 \times 4$ & 4 & 2 & 50 & 60 & (G) \\
$11 \times 4$ & 2 & 0 & 0 & - & - \\
\hline
\end{tabular}

MS: muita semente

(G) : germinação tardia, 15 dias após o plaqueamento

Tabela 10 - obtenção das gerações $\mathrm{F}_{2}$ e de retrocruzamento para C. anguria a partir da hibridação interespecífica C. anguria $\times$ C. ficifolius, expressa em pegamento de fruto (o.). Ilha SoIteira, SP, 1987.

\begin{tabular}{lcccc}
\hline $\begin{array}{c}\text { Combinação } \\
\text { parental }\end{array}$ & $\begin{array}{c}\text { No de } \\
\text { polinizaçães }\end{array}$ & $\begin{array}{c}\text { No de } \\
\text { frutos }\end{array}$ & $\begin{array}{c}\text { Pegamento } \\
\text { de fruto (\%) }\end{array}$ & Observação \\
\hline $10 \times 4$ (3) & 7 & 4 & 57,1 & MS, SN \\
$10 \times(10 \times 4)$ & 11 & 4 & 36,4 & MS, SN \\
\hline
\end{tabular}

MS : muita semente

SN: semente normal 
NIJS \& VISSER, 1985).

Assim, pode-se supor que C. ficifolius utilizada no presente trabalho, embora se assemelhe à descrição apresentada por DEAKIN (1971), esteja erroneamente clas sificada e se trate de uma introdução de C. anguría, consi derando-se a semelhança morfológica dessas duas espécies e a produção de gerações $F_{1}, F_{2}$ e de retrocruzamentos férteis após o cruzamento mencionado.

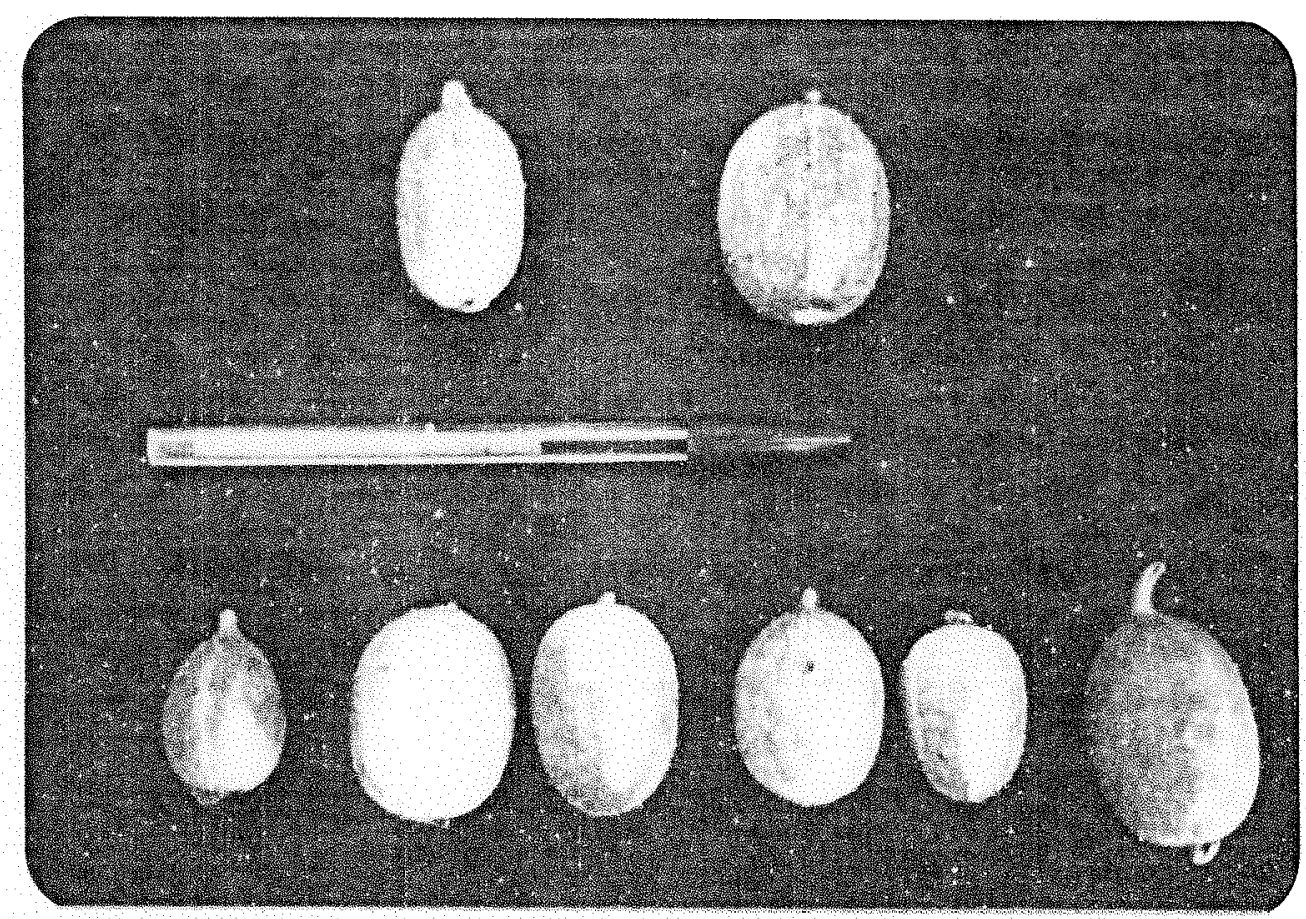

Foto 2 - Na parte superior: C. anguria (à esquerda) e a es pécie classificada como C. ficifolius (à direita); Na parte inferior: hỉbridos $F_{1}$ obtidos

4.1.4. Cruzamento de $c$. anguria $\times c$. longipes

A hibridação entre C. anguria x c: longipes 
foi executada com muito êxito, obtendo-se alta porcentagem de pegamento de frutos $(84,628)$ e produção abundante de sementes normais, em ambas as dìreções de cruzamento (Tabelas 11 e 12). Confirma-se, porttanto, a experiência de diversos autores que relatain a facilidade de cruzamento entre essas espécies e a alta produção de sementes em cruzamentos recĩprocos (MEEUSE, 1954; DEAKIN et alii, 1971; NIJS \& VISSER, 19.85), que, no entanto, utilizaram introduções africanas de ambas as espécies progenitoras.

\section{Pela Tabela 13 pode-se constatar a possibili} dade de obtenção de gerações $\mathrm{E}_{2}$ a partir do híbrido interes pecífico. Constituern exceções as combinações 13 x 5 e 14 x 6 , cujos baixos indices de pegamentos de frutos podem ser atribuídos a uma infestação severa de pulgões, que prejudicou o desenvolvimento dos frutos.

Os demais hibridos foram vigorosos e férteis, apresentando características de frutos intermediārios aos pais, numa grande variedade de tipos ou fenötipos (Foto 3).

Os resultados, de acordo com os reportados na literatura, convergem nas conclusões de MEEUSE (1954), que considera $c$. longipes o ancestral do maxixe e sugere que as espécies sejam antes reconhecidas como variedades de uma ünica espécie, ou sejja, C. anguria var. anguria e C. anguria var. longipes. 
Tabela 11 - Eibrjação interespecífica de C. anguria $x$ C. longipes, expressa em pegamento de fruto (:). Piracicaba, SP, 1986.

\begin{tabular}{|c|c|c|c|c|c|}
\hline $\begin{array}{l}\text { Combinação } \\
\text { parental }\end{array}$ & $\begin{array}{c}\text { No de } \\
\text { polinizações }\end{array}$ & $\begin{array}{l}\text { No de } \\
\text { fnutos }\end{array}$ & $\begin{array}{l}\text { Pegamento } \\
\text { de fruto }\left(\frac{\circ}{0}\right)\end{array}$ & $\begin{array}{c}\text { Germinação } \\
(\%)\end{array}$ & observação \\
\hline $10 \times 5$ & 4 & 4 & 100 & 86,7 & MS \\
\hline $10 \times 6$ & 4 & 3 & 75 & - & MS \\
\hline $11 \times 5$ & 2 & 2 & 100 & 50,0 & $S N, S R$ \\
\hline $12 \times 6$ & 2 & 2 & 100 & - & - \\
\hline $13 \times 5$ & 5 & 5 & 100 & 40,0 & MS \\
\hline $14 \times 5$ & 2 & 2 & 100 & 100,0 & MS \\
\hline $15 \times 5$ & 1 & 1 & 100 & - & - \\
\hline $15 \times 6$ & 6 & 3 & 50 & 100,0 & MS \\
\hline Gexal & 26 & & 84,62 & & \\
\hline $\begin{array}{l}\text { SN: semente } \\
\text { SR: semente } \\
\text { MR: muita } \\
\text { Tabela } 12 \text { - }\end{array}$ & $\begin{array}{l}\text { e normal } \\
\text { e rudimentar } \\
\text { semente } \\
\text { - Hibridação } \\
\text { anguria, e } \\
\text { Piracicaba }\end{array}$ & $\begin{array}{l}\text { intert } \\
\text { xpress } \\
\text { SP, }\end{array}$ & $\begin{array}{l}\text { específica } \\
\text { a em pegame } \\
1986 .\end{array}$ & $\begin{array}{l}\text { de } c \text {. long } \\
\text { ento de fru }\end{array}$ & $\begin{array}{l}\text { jipes } x \quad \text {. } \\
\text { ato }\left(\frac{c}{8}\right) \text {. }\end{array}$ \\
\hline $\begin{array}{l}\text { Combinação } \\
\text { parental }\end{array}$ & $\begin{array}{l}\text { No de } \\
\text { polinizą }\end{array}$ & Des $\quad \mathrm{N}$ & $\begin{array}{l}\text { Peg de } \\
\text { rutos de } \mathrm{fx}\end{array}$ & $\begin{array}{l}\text { gamento } \\
\text { ruto (\%) }\end{array}$ & coservação \\
\hline $6 \times 10$ & 3 & & 3 & 100,0 & MS \\
\hline $5 \times 12$ & 3 & & 2 & 66,7 & MS \\
\hline $6 \times 14$ & $I$ & & 1 & 100,0 & MS \\
\hline Geral & 7 & & & 85,73 & \\
\hline
\end{tabular}

MS: muita semente 
Trabela 13 - obtenção das gexações F2 e de retrocruzamento para C. anguria a partir da hibridação interespecifica $C$. anguria $\times C$. longipes expressa em pegamento de fruto (\%). Inha Solteira, SP,1987.

\begin{tabular}{|c|c|c|c|c|}
\hline $\begin{array}{c}\text { Combinação } \\
\text { parental }\end{array}$ & $\begin{array}{c}\text { No de } \\
\text { polinizações }\end{array}$ & \multirow[t]{2}{*}{$\begin{array}{l}\text { No de } \\
\text { Erutos }\end{array}$} & $\begin{array}{l}\text { Pegamento } \\
\text { de fruto } \\
\left(\frac{0}{0}\right)\end{array}$ & \multirow[t]{2}{*}{ Observação } \\
\hline $10 \times 5$ & 2 & & 50 & \\
\hline $11 \times 5(8)$ & 2 & 2 & 100 & $\mathrm{SN}, \mathrm{MS}$ \\
\hline $13 \times 5(3)$ & 3 & 0 & 0 & $\mathrm{PP}$ \\
\hline $14 \times 6 .(8)$ & 4 & 1 & 25 & $\mathrm{FP}, \mathrm{SN}, \mathrm{MS}$ \\
\hline $15 \times 6(8)$ & 4 & 4 & 100 & $\mathrm{SN}, \mathrm{MS}$ \\
\hline $6 \times 10(8)$ & 2 & 2 & 100 & $\mathrm{SN}$ \\
\hline $5 \times 12(8)$ & 2 & 1 & 50 & $-\infty$ \\
\hline $10 \times(10 \times 5)$ & 6 & 4 & 66,7 & - \\
\hline $11 \times(11 \times 5)$ & 3 & $I$ & 33,3 & - \\
\hline $13 \times(13 \times 5)$ & 1 & 1 & 100 & $\mathrm{SN}, \mathrm{MS}$ \\
\hline $14 \times(14 \times 6)$ & 3 & 3 & 100 & - \\
\hline
\end{tabular}

FP: frutos infestados por pulgões

$\mathrm{SN}$ : semente normal

MS : muita semente 


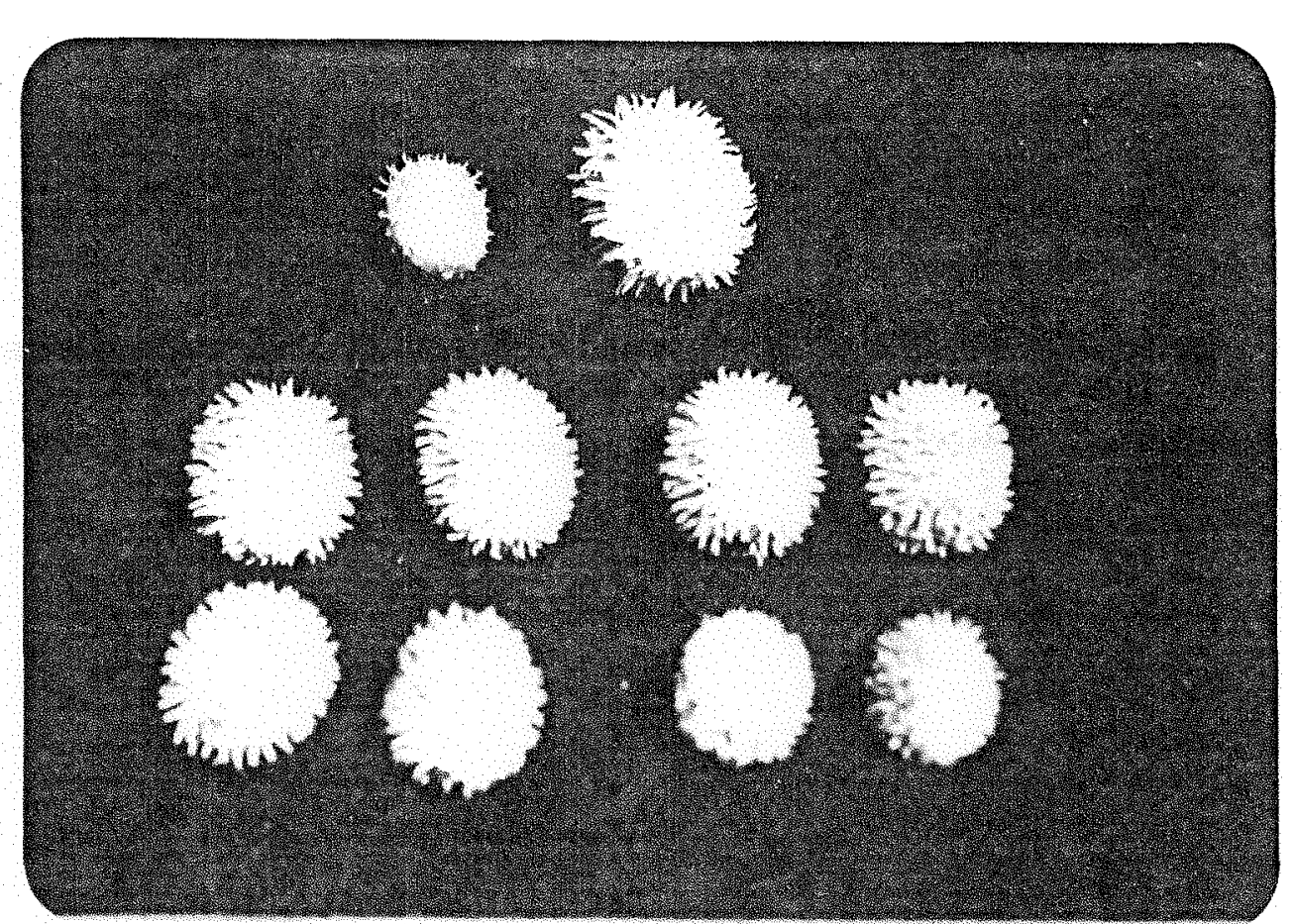

Foto 3 - Na parte superior: C. longipes (à esquerda) e C. anguria (à direita); na parte inferior: híbridos $F_{1}$ interespecíficos

Foi constatada a possibilidade de obtenção de gerações de retrocruzamento do híbrido interespecífico com C. anguria com produção de sementes normais (Tabela 13).

\subsubsection{Cruzamento de C. anguria $\times$ C. myriocarpus}

Foi possível a obtenção de hỉbridos entre C. anguria $\times$ C. meriocarpus concordando-se com os trabalhos de DEAKIN et alii (1971), KHO, NIJS \& FRANKEN (1980a), NIJS \& VISSER (1985). Das 30 polinizações efetuadas obtevese $70,0 \%$ de pegamento de frutos, sendo que o único cruzamen to que não produziu frutos foi $11 \times 8$. Foram produzidas poucas sementes em relação a C. anguria (Tabela 14). 
Tabela 14 - Hibridação interespecifica de C. anguria $x$ C. myriocarpus, expressa em pegamento de fruto (응. Piracicaba, SP, 1986.

\begin{tabular}{|c|c|c|c|c|c|}
\hline $\begin{array}{c}\text { Combinação } \\
\text { parental }\end{array}$ & $\begin{array}{c}\text { No de } \\
\text { polinizações }\end{array}$ & $\begin{array}{l}\text { No de } \\
\text { frutos }\end{array}$ & $\begin{array}{l}\text { Pegamento } \\
\left.\text { de Exuto( } \frac{(}{5}\right)\end{array}$ & $\begin{array}{c}\text { Germủnação } \\
\left(\frac{\circ}{1}\right)_{i}\end{array}$ & observação \\
\hline $10 \times 8$ & 2 & 2 & 100 & $26,7^{(G)}$ & - \\
\hline $10 \times 9$ & 9 & 5 & 55,5 & 46,7 & PS \\
\hline $11 \times 8$ & 2 & 0 & 0 & - & - \\
\hline $13 \times 9$ & 3 & 2 & 66,7 & 80,0 & PS \\
\hline $14 \times 8$ & 1 & 1 & 100 & 80,0 & PS \\
\hline $15 \times 8$ & 8 & 7 & 87,5 & 90,0 & PS \\
\hline $15 \times 9$ & 5 & 4 & 80,0 & - & - \\
\hline Geral & 30 & & 70,0 & & \\
\hline
\end{tabular}

PS: pouca semente

(G) : baixa porcentagem de germinação devido ao aparecimento de fungo na placa de petri

Pela Tabela 15 podemos observar que o cru zamento recíproco originou poucos frutos e poucas sementes, havendo combinações que resultaram em nenhum pegamento de frutos. Daí, conclui-se que C. myriocarpus funciona melhor como progenitor masculino em cruzamentos com C. anguria. KHO, NIJS \& ERANKEN (1980a) e NIJS \& VISSER (19 85) confir-. mam este fato, denominando o fenômeno de compatibilidade unilateral e atribuindo-se à inibição do tubo polínico no estilo de C. myriocarpus. 
NIJS \& VISSER (1981) observaram que C. muriọ carpus $\mathrm{x} C$. anguria produziram frutos sem sementes, engianto que o recíproco produziu progênies vigorosas. DEAKIN et alii (1971) relatam tambëm que C. myriocarpus x C. anguria produziram hỉbridos pouco fërteis. Mais uma vez as afirmações cor tidas na literatura referentes a hibridações entre espëcies africanas de Cucumis concordam com os resultados e observações obtidos com a utilização de introduções brasileiras de maxixe.

Tabela 15 - Hibridação interespecífica de C. myriocarpus x C. anguria, expressa em pegamento de fruto (\%). Piracicaba, SP, 1986.

\begin{tabular}{ccccc}
\hline $\begin{array}{c}\text { Combinação } \\
\text { parental }\end{array}$ & $\begin{array}{c}\text { No de } \\
\text { polinizações }\end{array}$ & $\begin{array}{c}\text { No de } \\
\text { frutos }\end{array}$ & $\begin{array}{c}\text { Pegamento } \\
\text { de fruto (?) }\end{array}$ & doservação \\
\hline $8 \times 10$ & 2 & 0 & 0 & - \\
$9 \times 10$ & 1 & 0 & 0 & - \\
$8 \times 12$ & 4 & 1 & 25 & PS \\
$9 \times 14$ & 1 & 0 & 0 & PS \\
$9 \times 15$ & 3 & 1 & 33,3 & \\
\hline Geral & 11 & & 18,17 & \\
\hline
\end{tabular}

PS: pouca semente

Os híbridos entre C. anguria e C. myriocar pus apresentaram Iistras vercie-escuras e espinhos semelhantes a C. myriocarpus mas tamanho de eruto maior, intermedia rio aos pais (F'oto 4 ). 


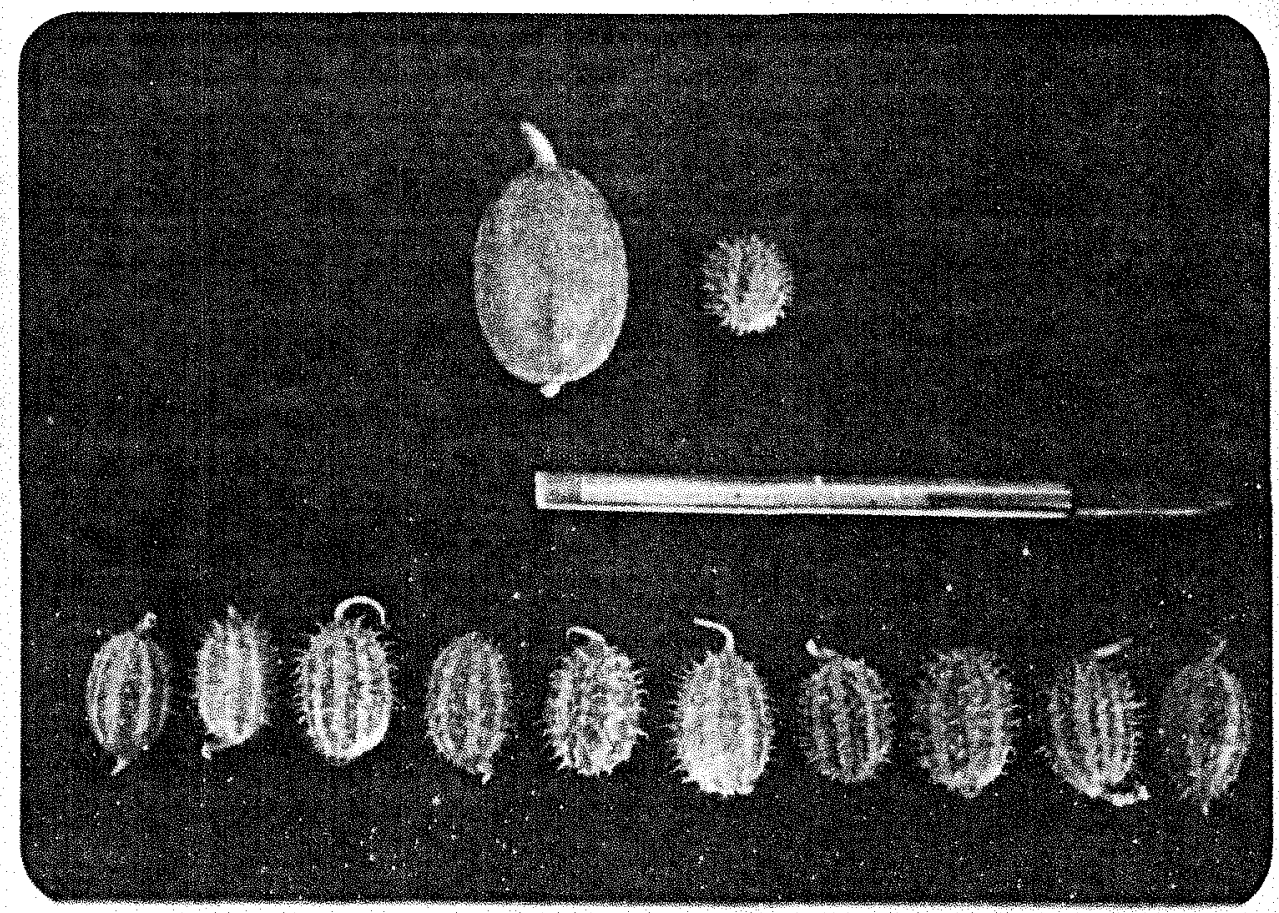

Foto 4 - Na parte superior: C. anguria (à esquerda) e C. myriocarpus (à direita): Na parte inferior: híbridos $F_{1}$ interespecíficos

Foram observadas duas plantas híbridas anômalas, com internódios curtos, folhas em "roseta", pouco desenvolvidas; com florescimento ṕrecoce e que não produziram frutos. Pode-se considerar que se trata de esterilidade do híbrido interespecífico ou efeito de genes deletērios.

Da Tabela 16 pode-se observar que por ocasião da auto-fecundação dos híbridos interespecíficos houve baixo índice de pegamento de frutos $(25,01 \%)$ e pequena produção de sementes, concordando com DEAKIN et alie (1971) 
e NIJS \& VISSER (1985). Alguns retrocruzamentos para C. anguria foram possĩveis, com boa produção de sementes normais.

$$
\text { Segundo relatos da literatura, C. myriocar- }
$$

pus carrega genes de resistência ao mosaico do pepino (CGN) e ao ácaro rajado (Tetranychus urticae) (KHROON et alie, 1979; DE PONTI, 1978), que, portanto, podem ser transferidos ao maxixe.

Tabela 16 - obtenção das gerações F'2 e de retrocruzamento para $C$. anguria a partir da hibridação interespecífica C. anguria x C. myriocarpus, expressa em pegamento de fruto (\%). Ilha solteira, SE, 1987 .

\begin{tabular}{|c|c|c|c|c|}
\hline $\begin{array}{l}\text { Combinaçäo } \\
\text { parental }\end{array}$ & $\begin{array}{c}\text { Ne de } \\
\text { polinizaç̄es }\end{array}$ & $\begin{array}{l}\text { No de } \\
\text { Enutos }\end{array}$ & 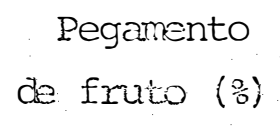 & Observação \\
\hline $10 \times 8$ & 11 & 6 & 54,5 & $F \mathrm{~F}, \mathrm{SN}, \mathrm{SR}$ \\
\hline $10 \times 9$ & 18 & 4 & 22,2 & PS, SN, SR \\
\hline $13 \times 9$ & 7 & 1 & 14,3 & $\mathrm{FA}, \mathrm{PS}$ \\
\hline $14 \times 8$ & 31 & 6 & 19,4 & PS, SN \\
\hline $15 \times 9(8)$ & 1 & 0 & 0 & - \\
\hline $10 \times(10 \times 8)$ & 5 & 3 & 60,0 & $\mathrm{SN}, \mathrm{MS}$ \\
\hline $10 \times(10 \times 9)$ & 11 & 4 & 36,4 & $S N, P S$ \\
\hline $13 \times(13 \times 9)$ & 10 & 1 & 10,0 & - \\
\hline
\end{tabular}

FP: fruto atacado por pulgão

PS: pouca semente

FA: fruto anômalo, pouco desenvolvido

MS: muita semente

SR: semente rudimentar

SN: semente normal 
4.1.6. Cxuzamento de C. africanus x C. myriocarpus

Pela Tabela 17 pode-se observar que as espëcies são compativeis em cruzamentos recíprocos, embora apenas uma introdução de cada espécie tenha sido utilizada.

Tabela 17 - Híbridação interespecífica de C. africanus $\mathrm{x} C$. myriocarpus (e reciproco) expressa em pegamento de fruto (\%). Piracicaba, SP, 1986.

\begin{tabular}{ccccc}
\hline $\begin{array}{c}\text { Combinação } \\
\text { parental }\end{array}$ & $\begin{array}{c}\text { No de } \\
\text { polinizaçöes }\end{array}$ & $\begin{array}{c}\text { No de } \\
\text { frutos }\end{array}$ & $\begin{array}{c}\text { Pegamento } \\
\text { de fruto (\%) }\end{array}$ & Observação \\
\hline $1 \times 8$ & 3 & 2 & 66,7 & SN, SR \\
$8 \times 1$ & 3 & 1 & 33,3 & SN, SR \\
\hline Geral & 6 & 50,0 & \\
\hline
\end{tabular}

SN : semente normal

SR: semente rudimentar

O híbrido mostrou grande desenvolvimento vegetativo, vigor, rusticidade e prolificidade consideráveis e características de Eruto intermediärias aos pais (Foto 5), alēm de exibir resistência à infestação natural de mosaíco da melancia e a D. bryoniae, não apresentando quaisquer sintomas.

Os reslithados diferem de NIJS et alii (1981) que ob tiveram hỉbridos entre C. muriocarpus e C. africanus, mas as sementes não germinaram ou originaram "seedlings" fra- 
cos que morriam após quatro semanas de crescimento. Nem a cultura de embrião teve sucesso, segundo o autor. Concluise que a possibilidade de cruzamento entre essas espécies depende da introdução utilizada.

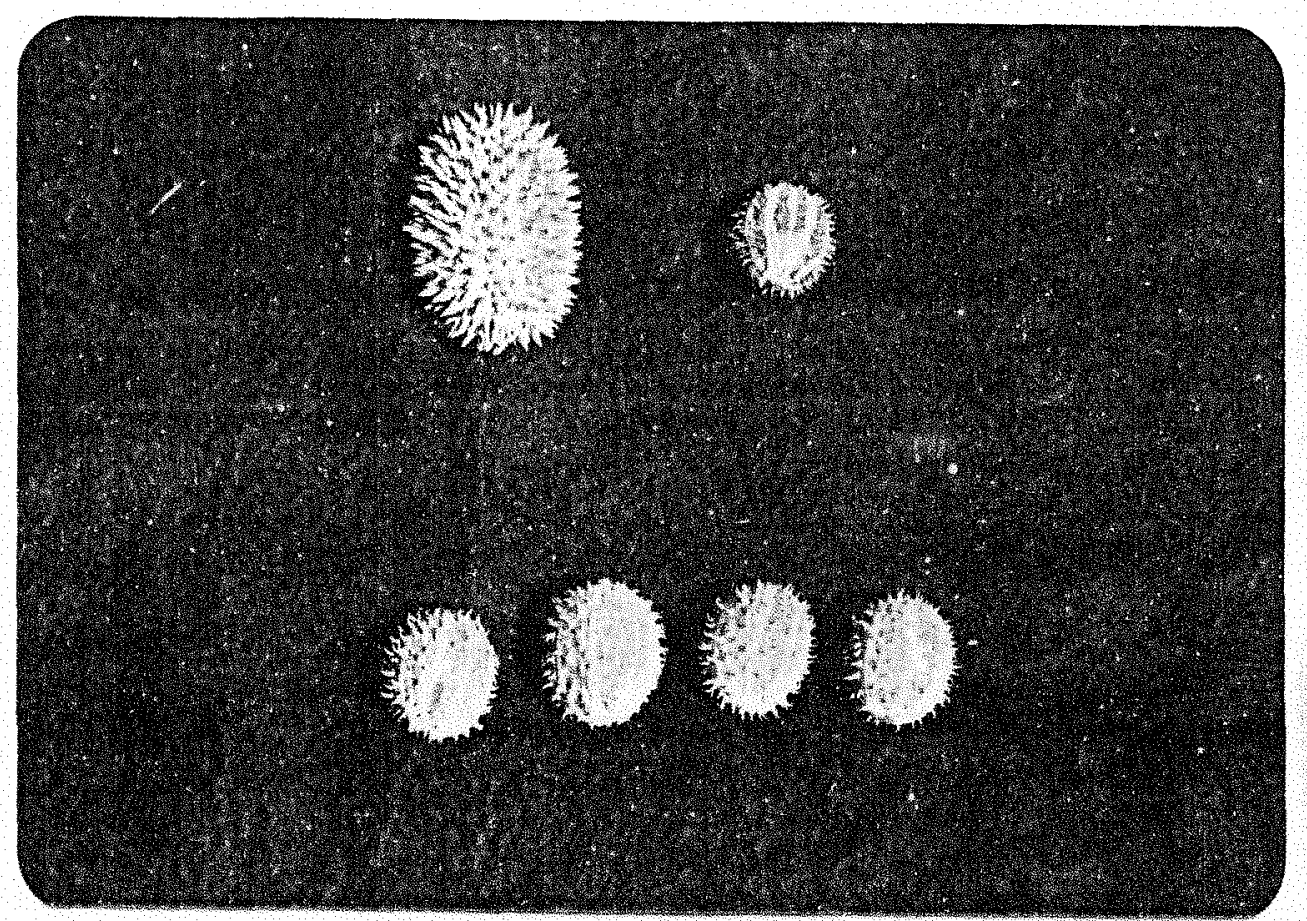

Foto 5 - Na parte superior: C. africanus (à esquerda) e C. myriocarpus (à direita); Na parte inferior: híbridos $F_{1}$ interespecíficos

KHO et alii (1980a) obtiveram híbridos entre C. africanus e C. myriocarpus, enquanto que o recíproco pro duziu ápenas frutos sem sementes. Já DEAKIN et alie (1971) relatam que os cruzamentos entre as espécies são possíveis em qualquer direção, mas os hỉbridos interespecíficos são pouco férteis. 
Foram ainda realizadas auto-fecundações do híbrido e cruzamentos com o maxixe nos 10 e 12, observando se produção de sementes normais.

$$
\text { Ressalta-se que este material pode desper- }
$$
tar grande interesse para utilização em programas de melhorą mento de espécies cultivadas de cucumis.

\subsubsection{Cruzemento de C. africanus $\times$ C. longipes}

De acordo com DEAKIN et alie (1971), C.afri. canus hibridizou com C. longipes, independente do progenitor feminino utilizado. Das 11 polinizações efetuadas foi obtido - Indice de 54,55\% de pegamento de frutos. Houve pequena pro dução de sementes, sendo que as sementes do cruzamento $5 \times 1$ não germinaram (Tabela 18).

E notāvel que C. africanus apresenta maior compatibilidade com $C$. anguria que com $C$. longipes, o que se verifica não só pelo maior pegamento de frutos mas também pe la maior quantidade e melhor qualidade das sementes oriundas do cruzamento $C$. anguria $\mathrm{x}$ C. africanus.

4.1.8. Cruzamento de C. dipsaceus $\mathrm{x}$ C. africanus

Não houve pegamento de frutos após este cruzamento (Tabela 19), embora segundo DEAKIN et alie (1981.) e 
Tabela 18 - Hibridação interespecífica de C. africanus $x$ C. C. longipes (e reciprocos), expressa em pegamento de fruto (\%). Piracicaba, SP, 1986.

\begin{tabular}{cccccc}
\hline $\begin{array}{c}\text { Combinação } \\
\text { parental }\end{array}$ & $\begin{array}{c}\text { No de } \\
\text { polinizaç̃̃es }\end{array}$ & $\begin{array}{c}\text { No de } \\
\text { frutos }\end{array}$ & $\begin{array}{c}\text { Pegamento } \\
\text { de futo }(\%)\end{array}$ & $\begin{array}{c}\text { Geminação } \\
(\%)\end{array}$ & Osservação \\
\hline $1 \times 5$ & 2 & 1 & 50,0 & - & PS \\
$1 \times 6$ & 3 & 2 & 66,7 & - & PS \\
$5 \times 1$ & 3 & 1 & 33,3 & 0 & SR \\
$6 \times 1$ & 3 & 2 & 66,7 & - & - \\
\hline Geral & 11 & & 54,55 & & \\
\hline
\end{tabular}

PS: pouca semente

SR: semente rudimentar

Tabela 19 - Hibridação interespecífica de C. dipsaceus $x$ C. africanus, expressa em pegamento de fruto (\%) Piracicaba, SP, 1986 .

\begin{tabular}{cccc}
\hline $\begin{array}{c}\text { Combinação } \\
\text { parental }\end{array}$ & $\begin{array}{c}\text { No de } \\
\text { polinizações }\end{array}$ & $\begin{array}{c}\text { No de } \\
\text { Erutos }\end{array}$ & $\begin{array}{c}\text { Pegamento } \\
\text { de fruto (\%) }\end{array}$ \\
\hline $3 \times 1$ & 4 & 0 & 0 \\
\hline
\end{tabular}

KHO et alii (1980) as espécies sejam compatíveis e produram bom nümero de sementes em cruzamentos recíprocos.

Ésta discordância de resultados pode. ser atribuỉa ao fato de apenas uma combinação ter sido utilizada, 
dificultando qualquer conclusão acexca do grau de comtabilidade interespecífica. Sugere-se que novas combinações sejam testadas.

4.1.9. Cruzamento de C. longipes x C. myriocarpus

De acordo com a Tabela 20 observa-se novamen te o fenômeno de incompatibilidade unidirecional em C. myrio carpus. Os cruzamentos utilizando-se C. myriocarpus como progenitor masculino tiveram sucesso, obtendo-se bom indice de pegamento de frutos, enquanto que o recíproco não produziu fruto algum. Mesmos resultados foram obtidos por DEAKIN et alii (1971).

4.1.10. Cruzamentos de C. metuliferus con outras espé cies de Cucumis sp.

C. metulifenus foi mais utilizada como progenitor masculino, não produzindo frutos apös cruzamento com c. africanus, c. ficifolius, c. longipes, c. myriocarpuse $c$. anguria (Tabela 2l).

Segundo DEAKIN et alii (1971), KH et alii (1980a)e NIJS \& VISSER (1985), C. metulíferus é uma espécie considerada geneticamente isolada de outras espécies africanas de Cucumis. No entanto, com a utilização de técnicas especiais de auxilio à polinização e de cultura de embrião cost 
Tabela 20- Hibridação interespecĩfica de C. longipes C. myriocarpus (e reciprocos) expressa em peganento de fruto (\%). Piracicaba, SP, 1986.

\begin{tabular}{cccc}
\hline $\begin{array}{c}\text { Combinação } \\
\text { parental }\end{array}$ & $\begin{array}{c}\text { No de } \\
\text { polinizaçöes }\end{array}$ & $\begin{array}{c}\text { No de } \\
\text { frutos }\end{array}$ & $\begin{array}{c}\text { Pegamento } \\
\text { deruto (\%) }\end{array}$ \\
\hline $5 \times 8$ & 3 & 2 & 66,7 \\
$6 \times 9$ & 1 & 1 & 100,0 \\
$6 \times 8$ & 4 & 2 & 50,0 \\
$8 \times 5$ & 4 & 0 & 0 \\
$9 \times 5$ & 5 & 0 & 0 \\
\hline Geral & 17 & & 29,42 \\
\hline
\end{tabular}

Tabela $2 I$ - Hibridação interespecifica utilizando-se C. metuliferus, expressa em pegamento de fruto $(\%)$. Piracicaba, SP, 1986 .

\begin{tabular}{cccc}
\hline $\begin{array}{c}\text { Combinação } \\
\text { parental }\end{array}$ & $\begin{array}{c}\text { No de } \\
\text { polinizaçöes }\end{array}$ & $\begin{array}{c}\text { No de } \\
\text { frutos }\end{array}$ & $\begin{array}{c}\text { Pegamento } \\
\text { deruto }\end{array}$ \\
\hline $7 \times 1$ & 1 & 0 & 0 \\
$1 \times 7$ & 1 & 0 & 0 \\
$4 \times 7$ & 3 & 0 & 0 \\
$6 \times 7$ & 2 & 0 & 0 \\
$9 \times 7$ & 1 & 0 & 0 \\
$10 \times 7$ & 3 & 0 & 0 \\
$12 \times 7$ & 3 & 0 & 0 \\
$14 \times 7$ & 1 & 0 & 0 \\
$15 \times 7$ & 4 & 0 & 0 \\
\hline
\end{tabular}


\& NIJS (1979), CUSTERS \& Ee (1980), NIJS et alii (1980) e CUSTERS et alii (1981) tiveram sucesso no cruzamento entre c. metuliferus e C. africanus. Esta hibridação visa a incorporar resistência a nematóides do gênero Meloidogunne presente em C. metuliferus e resistência a CGMV de C. africanus às espécies cultivadas de cucumis, principalmente ao pepino.

4.2. Auto-fecundações das espécies progenitoras utilizadas na hibridação interespecỉica

A Tabela 22 apresenta os indices de pegamento de frutos após auto-fecundação das espécies progenitoras uti lizadas na hibridação interespecífica, podendo-se considerax. que houve $100 \%$ de pegamento para todas as espécies. Os Indices contidos nessa tabela for am considerados como "controle" ra análise e discussão dos resultados referentes à porcentagem de : pegamento de frutos das Tabelas de Hibridação Interespecífica. 
Tabela 22 - Auto-fecundações das espécies progenitoras uti lizadas na hibridação interespecífica, expres sas em pegamento de fruto (응. Piracicaba, SP, 1986.

\begin{tabular}{|c|c|c|c|c|}
\hline No & Espēcie & $\begin{array}{l}\text { No de } \\
\text { a uto- } \\
\text { fecun- } \\
\text { dações }\end{array}$ & $\begin{array}{l}\text { No de } \\
\text { frutos }\end{array}$ & $\begin{array}{c}\text { Pegamento } \\
\text { de Eruto } \\
(\%)\end{array}$ \\
\hline 1 & c. africanus & 5 & 5 & 100 \\
\hline 2 & c. dipsaceus & - & - & - \\
\hline 3 & c. dipsaceus & 1 & 1 & 100 \\
\hline 4 & c. bicibolius & 2 & 2 & 100 \\
\hline 5 & c. longipes & 2 & 2. & 100 \\
\hline 6 & c. longipes & 4 & 4 & 100 \\
\hline 7 & C. metuliferus & 2 & 1 & 50 \\
\hline 8 & C. myriocarpus & 2 & 1 & 50 \\
\hline 9 & C. myriocarpus & 2 & 1 & 50 \\
\hline 10 & C. anguira & 5 & 5 & 100 \\
\hline 11 & C. anguria & 5 & 4 & 80 \\
\hline 12 & C. anguria & 2 & 1 & 50 \\
\hline 13 & C. anguria & 6 & 5 & 83,3 \\
\hline 14 & C. anguria & 5 & 5 & 100 \\
\hline 15 & C. anguria & 3 & 2 & 66,6 \\
\hline Geral & & 46 & & 84,77 \\
\hline
\end{tabular}


4.3. Avaliação do potencial de produção de frutos de alguns híbridos interespecificos no gênero cucumis

A análise de variância apresentada na Tabela 23 detectou diferenças altamente significativas entre trata mentos para os componentes de produção: nümero de frutos por parcela, rendimento, peso médio, diâmetro e comprimento do fruto. Pela decomposição dos tratamentos verificou-se que houve diferenças significativas entre as espécies, devido à grande diversidade que ocorre em Cucumis spp, bem como entre os híbridos interespēcificos avaliados, para todos os componentes. No entanto, não houve diferença entre os grupos (espécies versus híbridos), exceto para o caräter comprimento de fruto, que mostrou diferenças a nível de $5 \%$ de probabilidade.

As médias e as comparações entre elas através do Teste de Tukey são apresentadas na Tabela 24 .

Observa-se que a amplitude de prolificidade entre 40,67 e 245,00 frutos por parcela foi bastante acentuada. Entre as espécies nota-se dois grupos distintos de prolificidade: C. africanus e C. longipes representando um grupo de baixa prolificidade e C. anguria e C. myriocarpus apresentando alta prolificidade. Em relação aos híbridos in terespecificos, C. anguria x C. africanus e C. anguria $\mathrm{x} C$. myriocarpus mostraram-se pouco prolíficos. Neste último, 
a baixa prolificidade pode ser atribuída à debilidade do híbrido, uma vez que ambos os pais foram prolíficos. Já $C$. anguria $\times C$. longipes e C. africanus $\times$ C. myriocarpus produ ziram grande número de frutos por parcela, predominando a alta prolificidade de un dos pais.

Nota-se que o valor da diferença minima signi ficativa (dms) do Teste de Tukey foi bastante elevado, de maneira que grandes diferenças entre valores de nümero de frutos por parcela (por exemplo, 145,33 e 245,00) não foram significativos estatisticamente. Possivelmente este fato se deva ao pequeno nümero de repetições utilizado, sendo necessário un maior número para se detectar diferenças significativas mais precisas. Ressalta-se a grande prolificidą de do híbrido C. africanus x C. myriocarpus, com mëdia de 245,00 frutos por parcela, muito embora C. africanus tenha se situado no grupo de espécies de baixa prolificidade.

Em relação ao rendimento, observa-se que a espécie mais produtiva foi C. anguría, a espécie cultivada, e que a hibridaçäo desta espécie com C. africanus e com $C$. longipes não provocou decréscimo significativo de produção. Já o híbrido C. anguria x C. myriocarpus exibiram rendimen to significativamente menor do que $C$. anguria, pois as plan tas se mostraram fracas, pouco prolíficas e pouco férteis.

$$
\text { Nota-se que C. africanus e C. myriocarpus, in }
$$
cluidos em grupos distintos de prolificidade, apresentaram 
rendimentos semelhantes. Este fato ocorre porque C. africanus apresenta frutos grandes e de maior peso em menor quantidade, enquanto que C. myriocarpus produz grande número de frutos pequenos e de menor peso médio. A espécie C. longipes apresentou baixa produtividade devido à baixa prolifici dade, tamanho e peso de fruto reduzidos.

Quanto ao peso médio do fruto as espécies se dividem em três classes significativamente diferentes: de maior peso médio, C. africanus; de peso médio intermediārio, C. anguria; e de menor peso, C. longipes e C. myriocarpus. Entre os híbridos, C. anguria x C. africanus apresentou 0 maior peso médio, sendo o valor intermediário ao dos pais. Mais uma vez o híbrido $C$. anguria $\times$ C. longipes mostrou-se superior a C. longipes, produzindo frutos de peso médio seme lhante a C. anguria. Já os híbridos C. anguria x C. myriocar pus e C. africanus $\times$ C. myriocarpus produziram frutos de peso médio semelhante a $C$. myriocarpus, em detrimento às espécies maternais.

Analisando-se os componentes de produção diầmetro e comprimento do fruto observam-se comportamentos semelhantes. A espécie C. africanus apresentou os maiores valores, seguida de C. anguria e de C. longipes e C. myrio carpus, que não diferiram estatisticamente. O hïbrido C. an guria x C. africanus apresentou os maiores valores de diâmetro e comprimento de fruto, intermediários aos dos pais. 
A combinação C. anguria x C. longipes resultou em frutos de maior diâmetro e comprimento em relação a c. longipes. Observa-se que a significância obtida no efeito de grupos da anālise de variância (Tabela 23) se deve à superioridade deste híbrido em relação a C. longipes. Já os híbridos utilizando-se C. myriocarpus como polinizadoxa produziram frutos pequenos, com baixos valores de diâmetro e comprimento, que não diferiram dos valores de C. myriocarpus. 


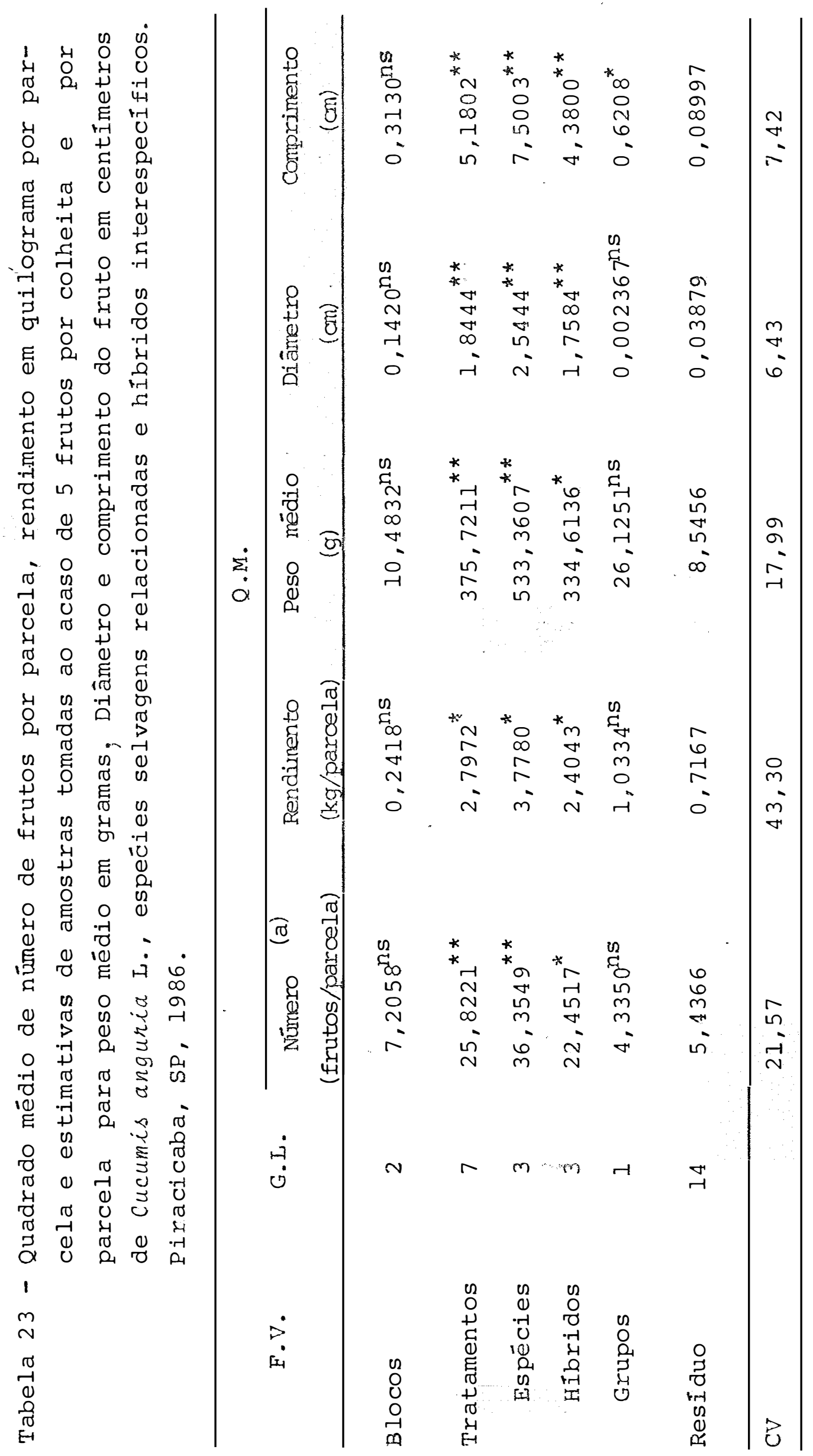




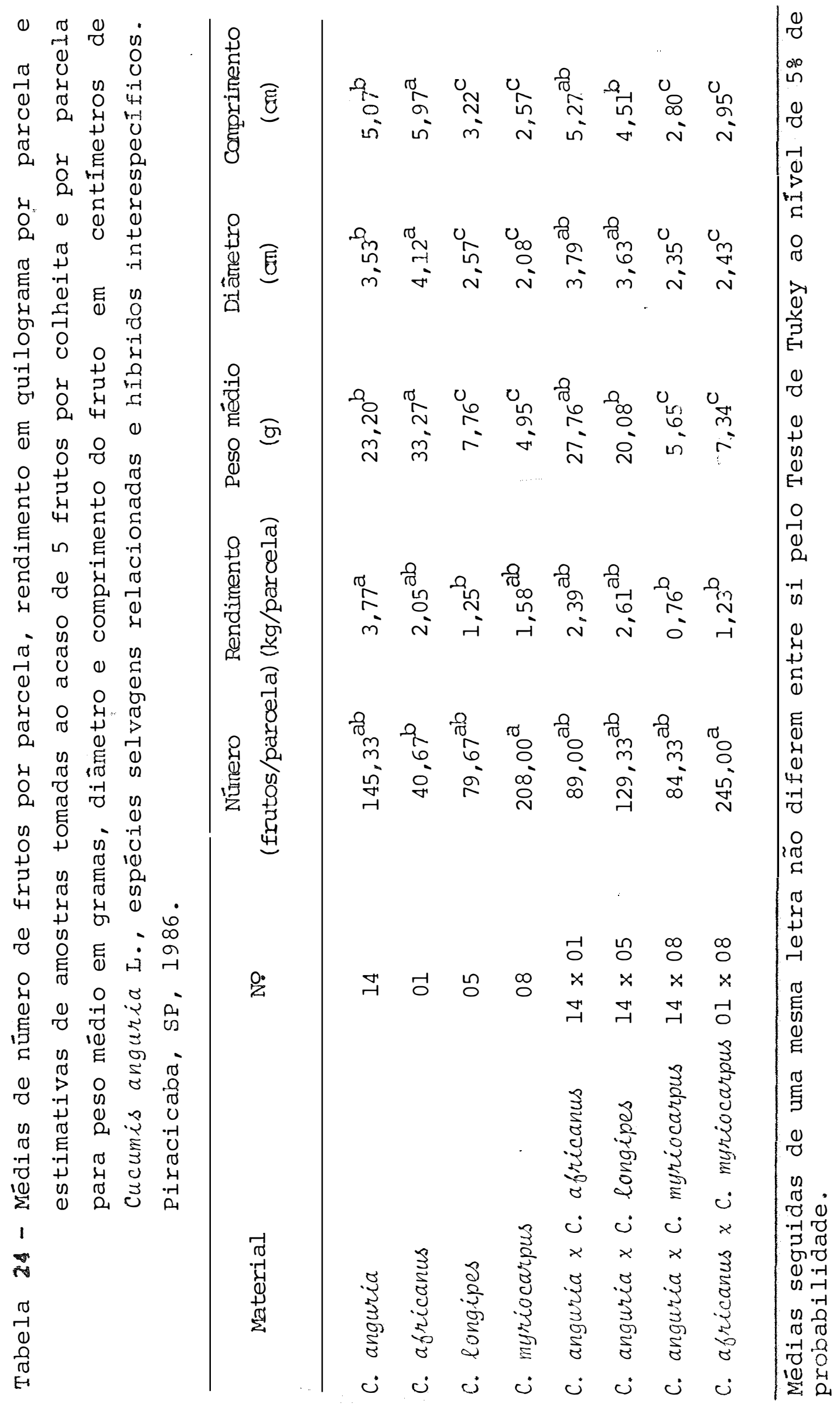




\section{CONCLUSOES}

Com base em observações e resultados obtidos no presente trabalho, foram estabelecidas as seguintes conclusões:

5.1. O maxixe apresenta grande compatibilidade com as es pécies C. longipes, C. myriocarpus e C. africanus, consta tando-se altos valores de indices de pegamento de frutos e produção de hỉbridos $F_{1}$ interespecíficos férteis.

5.2. O maxixe não é relacionado com C. dipsaceus.

5.3. As espécies selvagens C. africanus, C. longipes e c. myriocarpus são proximamente relacionadas.

5.4. C. metuliferus não se relaciona com as espécies utilizadas

5.5. C. africanus e C. muriocarpus devem ser utilizadas como progenitores masculinos em cruzamentos com o maxixe.

5.6. Todos os híbridos $\mathrm{F}_{1}$ interespecíficos obtidos apre sentaram características fenotípicas intermediärias aos progenitores, diferindo destes quanto à coloração, espiculosida cie e comprimento do fruto. 
5.7. Foi possivel a obtenção de gerações segregantes $\mathrm{F}_{2}$ e de retrocruzamento para $\mathrm{C}$. anguria a partir dos hitridos $F_{1}$ interespecíficos $C$. anguria $x$ C. africanus, $C$. anguria $\mathrm{x} C$. longipes e C. anguria $\mathrm{x} C$. muriocarpus, re presentando grande potencial para utilização no melhoramento do maxixe. 


\section{LITERATURA CITADA}

ALLARD, R.W. Princípios do melhoramento genético das plantas. SP, Edgard Blücher, 1971. 381p.

BARHAN, W.S. The inheritance of a bitter principle in cucumbers. Proc. Amer. Soc. Hort. Sci., Geneva, 62:441$2,1953$.

BATES, L.S. \& DEYOTE, C.W. Wide hybridization and cereal improvement. Econ. Bot., New York, 27:401-12, 1973.

BATRA, S. Interspecific hybridization between muskmelon and cucumber. Journ. Hered., Washington, 45:24, 1954.

BHADURI, P.N. \& BOSE, P.C. Cytogenetical investigations in some commion cucurbits with special reference to fragmentation of chromosomes as a phisical basis of speciation. I. Genet., London, 48:237-56, 1948.

CUSTERS, J.B. \& Ee, G. Van. Reciprocal crosses between Cucumis africanus L. $f$. and C. metuliferus NAUD; II. Embryo development in vivo and in vitro. cuc. Gen. Coop. Rep., Madison, 3:50-1, 1980. 
CUSTERS, J.B.M.; NIJS, A.P.M. DEN; RIEPMA, P.W. Reciprocal crosses between Cucumis africanus L.f. and C. metuliforus; III. Effects of pollinations aids, physiological condition and genetic constitution of the maternal parent on crossability. Cuc. Gen. Coop. Rep., Madison, $\underline{4}$ : 50-3, 1981.

CUSTERS, J.B.M. \& NIJS, A.P.M. DEN. Effects of aminoethoxyvinylglycine (AVG), environment and genotype in overcoming hybridization barriers between Cucumis species. Euphytica, Wageningen, $\underline{35}: 639-47,1986$.

DEAKIN, J.R. ; BOHN, G.W.; WHITAKER, W. Interespecific hybridization in Cucumis. Econ. Bot., Bronx, 25:195-211, 1971.

ESQUINAS-ALCAZAR, J.T. \& GULICK, P.J. Genetic resources of cucurbitaceae. Rome, International Board for Plant Genetic Resources, 1983. $101 \mathrm{p}$.

FRATIN, P. Informação pessoal.

GARCIA-SOGO, M. ; GRANELLI, I.; GARCIA-SOGO, L . ; ROIG, A. \& MORENO, V. Plants regeneration from explant-derived calli of Cucumis anguria L. var. longipes. Cuc. Gen. Coop. Rep., Madison, 9: $108-9,1986$.

GOMES, F.P. Curso de estatística experimental. 6a ed. São Paulo, Nobel, 1976, 430p. 
GRANBERRY, D.M. \& NORTON, J.D. Response of progeny from interespecific cross of Cucumis melo $x$ C. metuliferus to Meloidogyne incognita acrita. J. Amer. Soc. Hort. Sci., Geneva, $105(2): 180-3,1980$.

HADLEY, H.H. \& OPENSHAW, S.J. Interespecific and intergeneric hybridization. In: FEHR, W.R. \& HADLEY, H.H. ed. Hybridization of Cxop. Plants. American Society of Agronomy and Crop Science Society of America, Madison. p. $133-60,1980$.

HARLAN, J.R. Genetic resources in wild relatives crops. Crop. Sci., Madison, 16:329-33, 1976 .

KHO, Y.O.; NIJS, A.P.M. DEN; FRANKEN, J. Interespecific hybridzation in Cucumis L.; II. The crossability of species, an investigation of in vivo pollen tube growth and seed set. Euphytica, Wageningen, 29:661-72, 1980a.

KHO, Y.O.; NIJS, A.P.M. DEN; FRANKEN, J. In vivo pollen tube growth as a measure on interspecific incomgruity in Cucumis L. Cuc. Gen. Coop. Rep., Madison, 3:52-4, $1980 \mathrm{~b}$.

KHO, Y.O.; FRANKEN,J.; NIJS, A.P.M. DEN. Species crosses under controlled temperature conditions. Cuc. Gen. Coop. Rep., Madison, $4: 56-7,1981$. 
KROON, G.H.; CUSTERS, J.B.M.; KHO, Y.O.; NIJS, A.P.M. DEN \& VAREKAMP, H.Q. Interspecific hybridization in Cucumis L.; I. Need for genetic variation, biosystematic relations and possibilities to overcome crossability barriers. Euphytica, Wageningen, 28:723-28, 1979.

LEEUWEN, L. VAN \& NIJS, A.P.M. DEN. Probiems with the identification of Cucumis L. taxa. Cuc. Gen. Coop. Rep. Madison, $\underline{3}: 55-9,1980$.

LEPPIK, E.E. Searching gene centers of the genus Cucumis through host-parasite relationship. Euphytica, Wageningen, $1 \underline{5}: 323-8,1966$.

LOWER, R.L. \& EDWARDS, M.D. Cucumber breeding. In: BASSETT, M.J. ed. Breeding Vegetable Crops, Wesport, AVI, 1986, p. 173-207.

MALLICK, M.F.R. \& MASUI, G.N. Oxigin, distribution and taxonomy of melons. Scientia Horticulture, Amsterdam, 28:251-61, $198 \dot{6}$.

MEEUSE, A.D.J. The possible origin of Cucumis anguria L. Blumea, 4:196-205, 1958.

NIEMIROWICZ-SZCYTT, K.A.W. Intergeneric and interspecific crosses in cucurbitaceae. Incompat. Newsletter, 7: 75-7, 1976. 
NIJS, A.P.M. DEN \& OOST, E.H. Effect of Mentor Pollen on pistil-pollen incongruities among species of Cucumis L. Euphytica, Wageningen, 29:267-71, 1980.

NIJS, A.P.M. DEN; CUSTERS, I.B.M.; ROOISTRA, A.J. Reciprocal crosses between Cucumis africanus L.f. and C. metuliferus NAUD I. Overcoming barriers to fertilization by mentor pollen and AVG. Cuc. Gen. Coop. Rep., Madison, 3:60-2, 1980 .

NIJS, A.P.M. DEN; VISSER, D.L.; CUSTERS, J:B.M. Seedling death in interspecific crosses with cucumis africanus L.f. Cuc. Gen. Coop. Rep., Madison, 4 :58-60, 1981.

NIJS, A.P.M. DEN. Inheritance of resistance to cucumber green mottle mosaic virus (C.gm.) in Cucumis anguria L. Cuc. Gen. Coop. Rep., Madison, 5:57-8, 1982 .

NIJS; A.P.M. DEN \& VISSER, D.L. Relationship between african species of the genus Cucumis $L$. estimated by the production, vigour and fertility of $\mathrm{F}_{I}$ hybrids. Euphytica, Wageningen, 34: $279-90,1985$.

NORTON, J.D. \& GRANBERRY, D.M. Characteristics of progeny from a interspecific cross of Cucumis melo with c. metuliberus. J. Amer. Soc. Hort. Sci., Geneva, 105(2):174-80, 1980 
OOST, E.H. \& NIJS, A.P.M. DEN. Mentor pollen as a tool in interspecific hybridization in Cucumis. Cuc. Gen. Coop. Rep., Madison, 2:43-4, 1979.

PITRAT, M. \& VAULX, R.D. de. Disease resistances in some wild Cucumis species. Cuc. Gen. Coop. Rep., Madison, $\underline{2}: 44-5,1979$.

PONTI, O.M.B. de Resistance in $C$. sativus $L$. to Tetranychus urticae $\mathrm{KOCH}$. I. Search for sources of resistance. Euphytica, Wageningen, 27:167-76, 1978.

ROBINSON, R.W. \& KOWALEWSKI, E. Interspecific hybridization of Cucumis. Cuc. Gen. Coop. Rep., Raleigh, 1:40, 1978.

STALKER, H.T. Utilizations of wild species for crop improvement. Advances in Agronomy; New York, 33:111-47, 1980 .

STEBBINS, G.L. The inviability weakness and sterility of interspecific hybrids. Adv. Gen., New York, 9:147-215, 1958.

STEEL, R.G.D. \& TORRIE, J.H. Principles and procedures of statistics. New York, McGraw-Hill, 1960, 481p.

TRIVEDI, R.N. \& ROY, R.P. Cytological studies in Cucumis and Citrullus. Cytologia, Tokyo, 35:561-9, 1970. 
VISSER, D.L. \& NIJS, A.P.M. DEN. The Cucumis species collection at the IVT. Cuc. Gen. Coop. Rep., Madison, $3: 68-9,1980$.

WHITAKER, T.W. \& DAVIS, G.N. Cucurbits; botany, cultivation and utilization. New York, Interscience, 1962, 250p.

YOKOYAMA, S. Aspectos genéticos de maxixe (Cucumis anguria

L.) e produção de sementes. Piracicaba, 1987. 113p. (Dou torado - Escola Superior de Agricultura "Luiz de Queiroz"/ USP) . 